Universidade de São Paulo

Faculdade de Medicina de Ribeirão Preto

\title{
Análise biomecânica do ombro de \\ nadadores após a realização de um \\ teste de esforço máximo
}
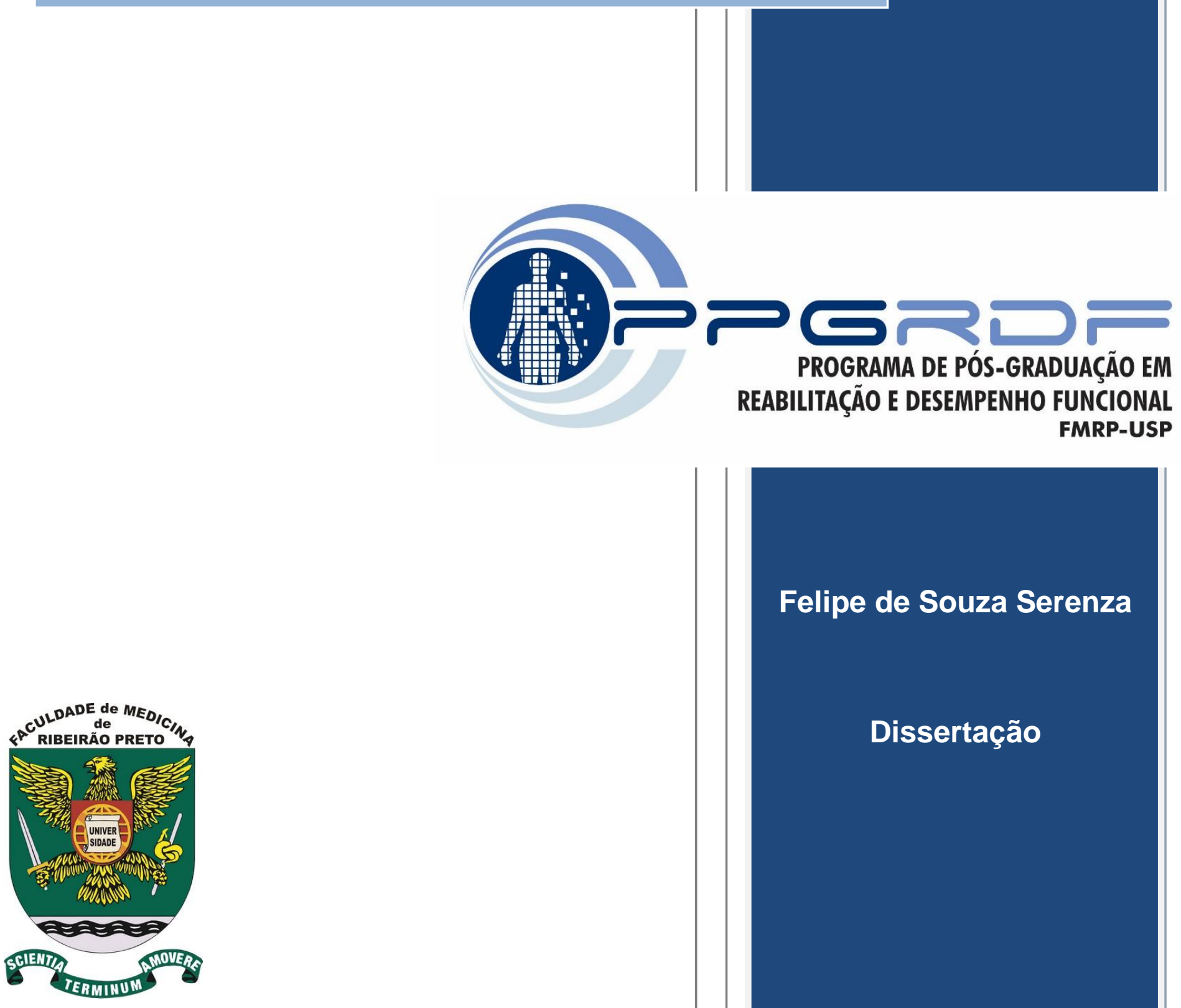

Dissertação 
UNIVERSIDADE DE SÃO PAULO

FACULDADE DE MEDICINA DE RIBEIRÃO PRETO

FELIPE DE SOUZA SERENZA

Análise biomecânica do ombro de nadadores

Após a realização de um teste de esforço máximo

Ribeirão Preto - São Paulo 
FELIPE DE SOUZA SERENZA

\title{
Análise biomecânica do ombro de nadadores após a realização de um teste de esforço máximo
}

\author{
Versão original
}

Dissertação apresentada ao Programa de Pós-Graduação em Reabilitação e Desempenho Funcional da Faculdade de Medicina de Ribeirão Preto da Universidade de São Paulo para obtenção do título de Mestre.

Área de concentração: Fisioterapia

Orientador: Prof. Dr. Paulo Roberto Pereira Santiago

Colaboradora: Prof. Dra. Anamaria Siriani de Oliveira

Ribeirão Preto - São Paulo 
Autorizo a divulgação parcial ou total deste trabalho, por qualquer meio convencional ou eletrônico, para fins de estudo e pesquisa, desde que citada à fonte.

Catalogação na publicação

Serviço de Biblioteca e Documentação

Instituto de Psicologia da Universidade de São Paulo

Serenza, Felipe de Souza.

Análise biomecânica do ombro de nadadores após a realização de um teste de esforço máximo. Felipe de Souza Serenza; Orientador Paulo Roberto Pereira Santiago. -2017.

61 p. : il. ; $30 \mathrm{~cm}$

Dissertação de Mestrado - Programa de Pós-Graduação em Reabilitação e Desempenho Funcional da Faculdade de Medicina de Ribeirão Preto da Universidade de São Paulo, Ribeirão Preto, 2017. Área de concentração: Fisioterapia.

Versão original.

1. Cinemática. 2. Ombro 3. Natação. 4. Eletromiografia. 
Nome: SERENZA, Felipe de Souza

Título: Análise biomecânica do ombro de nadadores após a realização de um teste de esforço máximo.

Dissertação apresentada ao programa de Pósgraduação em Reabilitação e Desempenho Funcional da Faculdade de Medicina de Ribeirão Preto da Universidade de São Paulo para obtenção do título de Mestre.

Aprovado em:

Banca examinadora

Prof. Dr.

Instituição

Julgamento

Prof. Dr.

Instituição

Julgamento

Prof. Dr.

Instituição

Julgamento 


\section{Agradecimentos}

Agradeço a Deus por iluminar meu caminho e dar força nos momentos mais difíceis.

A minha mãe que desde sempre me deu apoio incondicional, e sempre sonhou junto comigo. Mãe, se eu cheguei aqui foi por suas mãos. Essa conquista é nossa.

A minha esposa Ligia que sempre esteve ao meu lado dando todo o suporte necessário. Sem você essa conquista seria muito mais difícil. Te amo!

Ao meu orientador Paulo Roberto Pereira Santiago que me abriu as portas do mundo acadêmico e me proporcionou todas as condições para meu aprendizado. Ao meu amigo Paulo Roberto Pereira Santiago, minha gratidão! Obrigado pelo companheirismo.

Aos meus companheiros de laboratório: Luis, Vitor, Tiago entre outros. Obrigado por toda a ajuda que vocês me deram. Ao meu amigo Rodrigo que me auxiliou na realização da estatística do trabalho, sua ajuda foi essencial. Um agradecimento especial para meu amigo Bruno que esteve sempre pronto a ajudar! Sem sua colaboração nas coletas esse trabalho não existiria. Ao meu grande amigo Fabio que esteve presente em todas as fases de meu mestrado. E ao Eduardo, técnico do laboratório, Du! Valeu. Muito obrigado a todos vocês meus amigos!

A professora Anamaria Siriane, que colaborou desde o início com este trabalho. Fica aqui minha gratidão.

Ao professor Marcelo Pappoti que me ajudou no recrutamento dos voluntários e disponibilizou parte dos equipamentos necessários para avaliações.

Ao colaborador Mr. Warner da University of Southampton. Mesmo sem me conhecer pessoalmente e estando tão longe, foi sempre absolutamente solícito e colaborou de maneira importantíssima com o estudo.

Aos meus colegas do Hospital das clínicas que sempre me apoiaram. E um agradecimento especial ao Fernando, engenheiro do Laboratório de Marcha do HCRP que me auxiliou muito com a parte de programação necessária nesse trabalho.

A escola de natação Pedro Baldo, em especial ao técnico Pedro que me auxílio com o recrutamento dos voluntários.

A todos meus sinceros agradecimentos, Vocês me deram a oportunidade de crescer como profissional! E ainda ganhei amigos para vida. 


\section{RESUMO}

SERENZA, S.S. Análise biomecânica do ombro de nadadores após a realização de um teste de esforço máximo. 2017. 58 f. Dissertação (Mestrado) - Faculdade de Medicina de Ribeirão Preto, Ribeirão Preto-SP, 2017.

A prevalência de dor no ombro em nadadores competitivos pode chegar a $91 \%$. A articulação escapulotorácica (ET) tem papel central na funcionalidade do ombro atuando de forma coordenada com a articulação glenoumeral (GU), posicionando a cavidade glenóide para evitar impacto precoce do manguito rotador (MR) sob o arco coracoacromial. Um atleta de natação pode realizar até 2500 braçadas em apenas um dia de treinamento o que os torna susceptível a fadiga. $\mathrm{O}$ objetivo deste estudo foi analisar a cinemática da escápula e atividade eletromiográfica dos músculos trapézio ascendente (TA), trapézio transverso (TT), trapézio descendente (TD) e serrátil anterior (SA) em nadadores antes e após a realização de um teste de esforço máximo de 3 minutos. O estudo contou com 16 atletas entre 15 a 24 anos. Um sistema de 8 câmeras infravermelho foi utilizado para registrar a cinemática nos três planos de movimento antes e após o teste de esforço. Foi utilizado um eletromiógrafo com sensores wireless sincronizado ao sistema de câmeras. A análise estatística para comparação entre o pré e pós teste foi realizada pelo teste $t$ pareado e a estimativa do tamanho do efeito (TE) foi calculada pelo $d$ Cohen's. Foram realizadas regressões lineares para verificar a relação entre a variação cinemática e a variação eletromiográfica. Os resultados mostraram aumento da rotação interna da escápula em todas as angulações com TE pequeno, e aumento da inclinação anterior com $120^{\circ}$ de elevação com TE pequeno. O SA apresentou diminuição da atividade eletromiográfica nos intervalos de $120-90^{\circ}$ e $60-30^{\circ}$ com TE moderado. Houve relação entre a variação da inclinação anterior da escápula e a variação da atividade muscular do TT, da rotação interna com a variação do TT e do SA. Concluiu-se que atletas de natação submetidos a um teste de esforço máximo exibem aumento da inclinação anterior, além de aumento da rotação interna durante toda a ADM. A atividade muscular do SA decaiu após o teste de esforço máximo. Por se tratar de um músculo atuante durante todo o gesto esportivo, estratégias preventivas e de tratamento devem focar no ganho de força e resistência deste músculo.

Palavras chave: Cinemática. Ombro. Natação. Eletromiografia. 


\begin{abstract}
SERENZA, S.S. Biomechanical analysis of the swimmers's shoulder after performing a maximal effort test. 2017. 58 f. Dissertação (Mestrado) - Faculdade de Medicina de Ribeirão Preto, Ribeirão Preto-SP, 2017.

The prevalence of shoulder pain in competitive swimmers may reach $91 \%$. The scapulothoracic joint (ST) plays a central role in shoulder function acting in a coordinated way with the glenohumeral joint (GU), avoiding the impact on the rotator cuff (MR) under the coracoacromial arch. A swimming athlete can perform up to 2.500 strokes in just one day of training which makes them susceptible to fatigue. The aim of this study was to analyze the scapular kinematics and the electromyographic activity of the upper trapezius (UT), medium trapezius (MT), lower trapezius (LT) and anterior serratus (AS) muscles in swimmers before and after a maximal effort in a 3 minutes test. The study included 16 athletes aged between 15 and 24 years. A system with 8 infrared camera was used to verify the kinematics in the three planes of motion before and after the effort test. A wireless electromyograph synchronized with the camera system was used. The statistical analysis for comparison between the pre and post test was performed by the paired T-test and the effect size calculation (ES) was performed by d Cohen's. Linear regressions were performed to verify the relationship between the kinematic variation and the electromyographic variation. The results showed increased scapular's internal rotation at all angles with small ES and anterior tilt increase at $120^{\circ}$ elevation with small ES. The AS showed a decrease in electromyographic activity in the intervals of $120-90^{\circ}$ and $60-30^{\circ}$ with moderate ES. There was a relation between the variation of the anterior tilt of the scapula and the variation of the MT muscle activity, between the internal rotation with the MT and between the internal rotation with AS muscle variation. Was concluded that swimming athletes submitted to a maximal effort test showed an increase in anterior tilt, in addition to an increase in internal rotation throughout all the range of motion. The AS muscle activity declined after the maximal effort test. Because it is a active muscle throughout the stroke movement, preventive and treatment strategies should focus on the strength and endurance of this muscle.
\end{abstract}

Keywords: Biomechanics. Shoulder. Swimming. Electromyography. 


\section{LISTA DE TABELAS}

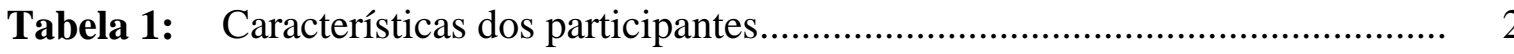

Tabela 2: Rotação interna da escápula. Valores negativos indicam rotação externa da escápula. No caso da diferença entre o pré e pós teste os valores negativos são referentes ao aumento da rotação interna no pós-teste .........

Tabela 3: Rotação superior da escápula. Valores negativos indicam rotação superior da escápula. No caso da diferença entre o pré e pós teste os valores são referentes ao aumento da rotação superior no pós-teste

Tabela 4: Inclinação anterior/posterior da escápula. Valores negativos indicam inclinação anterior da escápula. No caso da diferença entre o pré e pós teste os valores são referentes ao aumento da inclinação anterior no pósteste.

Tabela 5: Atividade eletromiográfica normalizada pela CVM durante os três intervalos de elevação umeral na fase descendente do movimento do braço 


\section{LISTA DE FIGURAS}

Figura 1: $\quad$ Fluxograma dos procedimentos

Figura 2: $\quad$ Clusters utilizados para realização da cinemática tridimensional da escápula. $\mathrm{A}=$ Humero marker cluster $(\mathrm{HMC}), \mathrm{B}=$ Acromion marker cluster $(\mathrm{AMC})$

Figura 3: Posicionamento dos marcadores do tórax, Humero marker cluster e Acromion marker cluster

Figura 4: Posicionamento do bastão de calibração. $B=$ círculos vermelhos representam os 5 pontos anatômicos discriminados durante a calibração

Figura 5: Posicionamento dos eletromiógrafos. $A=$ Trapézio ascendente (TA), trapézio transverso (TT) e trapézio descendente (TD). B= Serrátil anterior (SA)

Figura 6: Teste de esforço máximo de 3 minutos. $A=$ posição inicial, $B=$ posição média $e$ $\mathrm{C}=$ posição final

Figura 7: Tela inicial do aplicativo ShoulderModel.

Figura 8: $\quad$ Medidas angulares do movimento de rotação interna/externa da escápula em relação ao tórax durante o movimento de elevação e abaixamento do braço no plano da escápula

Figura 9: Medidas angulares do movimento de rotação superior da escápula em relação ao tórax durante o movimento de elevação e abaixamento do braço no plano da escápula

Figura 10: Medidas angulares do movimento da inclinação anterior em relação ao tórax durante o movimento de elevação e abaixamento do braço no plano da escápula

Figura 11: Root means square (RMS) dos músculos TD, TS, SA e TT durante o movimento do braço na fase descendente nas janelas de $120^{\circ}-90^{\circ}(\mathrm{A}), 90^{\circ}$ $60^{\circ}(\mathrm{B})$ e $60^{\circ}-30^{\circ}(\mathrm{C})$

Figura 12: Gráfico de dispersão da $\mathrm{VC}$ da inclinação anterior a $90^{\circ}$ e $60^{\circ}$ em relação à VAM do TT $120-90^{\circ}$ e TD 60-30. $R^{2}=$ coeficiente de correlação, $\mathrm{p}<0,05$

Figura 13: Gráfico de dispersão da $\mathrm{VC}$ da rotação interna a $120^{\circ}, 90^{\circ}, 60^{\circ}$ e $30^{\circ} \mathrm{em}$ relação à VAM do TT $120-90^{\circ}$ e TD 60-30. $\mathrm{R}^{2}=$ coeficiente de correlação, $\mathrm{p}<0,05$ 


\section{LISTA DE SIGLA}
AA:
Ângulo acromial

AC:

Acromioclavicular

ADM:

Amplitude de movimento

AIE:

Ângulo inferior da escápula

AMC:

Acromion Marker Cluster

CO:

Complexo do ombro

CRGU: Centro de rotação glenoumeral

CVM: $\quad$ Contração voluntária máxima

EC: $\quad$ Esternoclavicular

EEFERP: Escola de Educação Física e Esporte de Ribeirão Preto

EL: Epicôndilo lateral

EM: $\quad$ Epicôndilo medial

EMG: Eletromiografia

EP: $\quad$ Erro padrão

ET: $\quad$ Escapulotorácica

EVA Escala visual analógica

GU: Glenoumeral

HMC: $\quad$ Humero Marker Cluster

IC: $\quad$ Intervalo de confiança

IJ: Incisura jugular

ISB: International Sociaty of Biomechanics

LABIOCOM: Laboratório de Biomecânica e Controle Motor

MED: $\quad$ Média

MMSS: $\quad$ Membros superiores

MR: Manguito rotador

PE C-7: $\quad$ Processo espinhoso de C-7

PE T-8: $\quad$ Processo espinhoso de T-8

PX: $\quad$ Processo xifóide

RMS: $\quad$ Raiz Quadrada da Média

SA: $\quad$ Serrátil anterior

SCG: $\quad$ Sistema de coordenadas global

SCL: $\quad$ Sistema de coordenadas local 
SIS: $\quad$ Síndrome do impacto subacromial

TA: Trapézio ascendente

TD: Trapézio descendente

TE: Tamanho de efeito

TRE: Trígono da escápula

TT: $\quad$ Trapézio transverso

VAM: $\quad$ Variação da ativação muscular

VC: $\quad$ Variação cinemática 


\section{Sumário}

1. Introdução

2. Revisão da literatura ............................................................................. 15

2.1 Biomecânica da articulação ET................................................................... 15

2.1.1 Cinemática............................................................................. 15

2.1.1 Atividade muscular................................................................... 17

2.2 Alterações da biomecânica da articulação ET …………………………….. 17

2.2.1 Cinemática............................................................................... 17

2.1.1 Atividade muscular.................................................................... 18

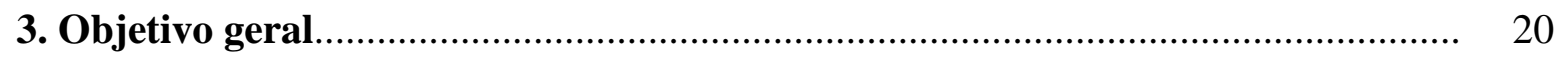

3.1 Objetivos específicos......................................................................... 20

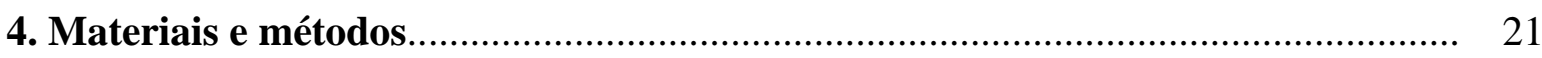

4.1 Aspectos éticos................................................................................ 21

4.2 Caracterização da amostra ...................................................................... 21

4.3 Critérios de inclusão................................................................................. 21

4.4 Critérios de Exclusão............................................................................ 22

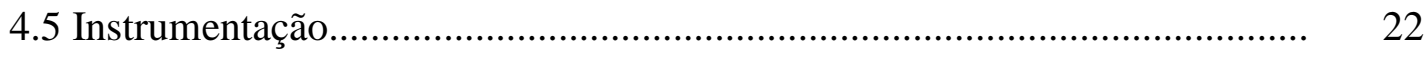

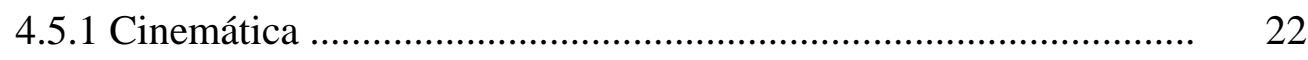

4.5.2 Eletromiografia......................................................................... 22

4.6 Procedimentos............................................................................ 23

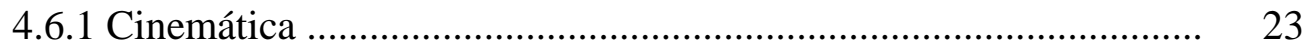

4.6.1.1 Sistemas de coordenadas................................................. 23

4.6.1.2 Cluster e tomada estática............................................. 23

4.6.1.3-Calibração e tomadas estáticas.................................... 24

4.6.1.4-Tomadas dinâmicas.................................................. 25

4.6.2 Eletromiografia ...................................................................... 25

4.6.3 Contração voluntária máxima......................................................... 26

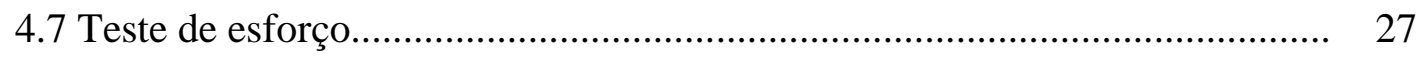

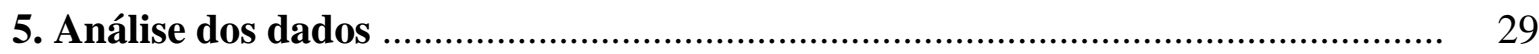

5.1 Cinemática ………………………………………………………..... 29

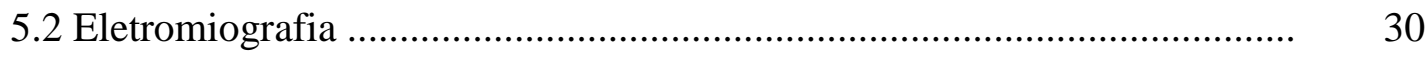

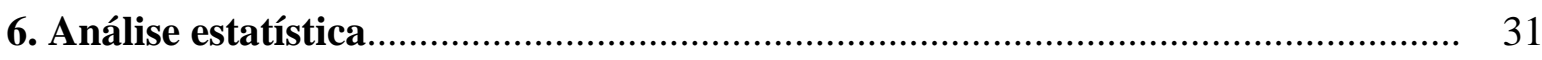

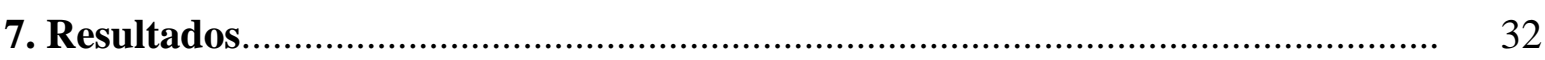


7.1 Cinemática........................................................................................ 32

7.1.1 Rotação interna da escápula......................................................... 32

7.1.2 Rotação superior da escápula....................................................... 33

7.1.3 Inclinação anterior/posterior da escápula....................................... 34

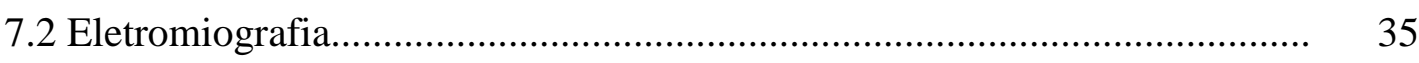

7.3 Poder explicativo da atividade muscular sobre a cinemática.......................... 37

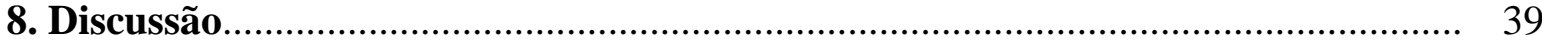

8.1 Limitações e considerações do estudo............................................................ 43

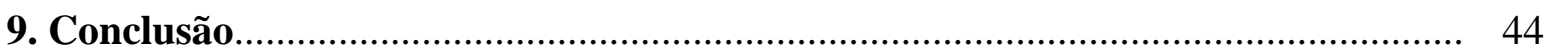

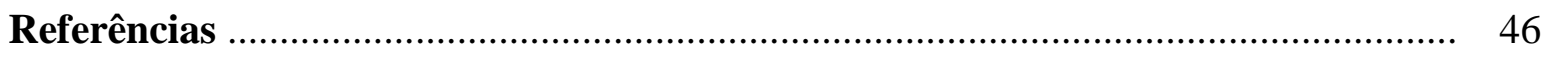

Anexo 1: Termo de assentimento livre e esclarecido dos voluntários.............................. 52

Anexo 2 : Termo de consentimento livre e esclarecido dos representantes legais ........... 54 


\section{INTRODUÇÃO}

A natação é um esporte caracterizado por movimentos cíclicos e coordenados entre os segmentos corporais. Dentre esses, os membros superiores (MMSS) são responsáveis por até 90\% da força de propulsão durante o nado livre (HEINLEIN; COSGAREA, 2010; PINK; TIBONE, 2000). Com isso, grandes cargas são impostas na articulação do ombro devido ao alto número de repetições do gesto esportivo durante treinamentos e competições (TOVIN, 2006). A presença de dor no ombro de nadadores de nível competitivo pode chegar a $91 \%$, sendo que até $69 \%$ têm sinais de tendinopatia de supraespinhal. A maior incidência de dor no ombro em nadadores é na faixa etária de 15-17 anos e no primeiro ano de universidade. Isso se deve ao grande aumento da carga de treinamento realizada nesses períodos (SEIN et al., 2010; WOLF et al., 2009).

O complexo do ombro (CO) é formado pelas articulações esternoclavicular (EC), acromioclavicular (AC), glenoumeral (GU) e escapulotorácica (ET). A função do CO é posicionar o membro superior durante a realização de atividades funcionais. De maneira conjunta as articulações do $\mathrm{CO}$ promovem grande amplitude de movimento (ADM) para os MMSS (TERRY; CHOPP, 2000).

A escápula faz contato com o tórax por meio da articulação ET e movimenta-se através da combinação de movimentos das articulações EC e AC (TEECE et al., 2008). A ET tem como característica anatômica pouca estabilidade osteoligamentar, o que a torna depende de estruturas musculares para garantir adequado posicionamento e movimentação (TERRY; CHOPP, 2000).

A articulação ET tem papel central na funcionalidade do CO (KIBLER; SCIASCIA, 2010). Ela movimenta-se de forma coordenada com a articulação GU, o que proporciona um melhor posicionamento da cavidade glenóide, assim pode evitar o impacto precoce das estruturas do manguito rotador (MR) sob o arco coracoacromial. Além disso, fornece base estável para inserção dos músculos do MR, que são importantes estabilizadores dinâmicos da articulação GU (KIBLER et al., 2013). Por fim, devido à localização anatômica da ET, tratase de um elo entre o tronco e os MMSS, sendo um ponto central da cadeia cinética na transmissão de forças entre os MMSS e o restante do corpo (RADWAN et al., 2014; WESTON et al., 2015).

Análises biomecânicas do ombro em nadadores já foram realizadas dentro da água (VIRAG et al., 2014). Porém um estudo específico da articulação ET não foi realizado, devido à dificuldade da captura dos dados nesta situação, e principalmente pela limitação dos 
métodos para estudo cinemático da articulação ET dentro e fora da água. Um dos cuidados nas avaliações cinemáticas da articulação ET é a realização abaixo da angulação de $120^{\circ}$ de elevação do ombro para obtenção de resultados confiáveis (KARDUNA et al., 2001; WARNER; CHAPPELL; STOKES, 2012). Desta maneira a análise durante o gesto da braçada não é viável. Com isso, avaliações cinemáticas da articulação ET são realizadas geralmente fora da piscina, em ambientes controlados e com movimentos constritos (LEMPEREUR et al., 2014).

A atividade muscular do CO durante a natação foi estudada por Pink et al. (1991a). Foram avaliados 12 músculos do CO em voluntários saudáveis durante o nado livre. Para tal análise foram utilizados eletromiógrafos intramusculares. A partir dos resultados foi possível se estabelecer um padrão das contrações musculares durante o gesto esportivo. Durante a fase aérea da braçada os músculos trapézio ascendente (TA) e serrátil anterior (SA) posicionam a articulação ET em rotação superior e rotação externa o que proporciona um posicionamento ótimo para articulação GU que está em máxima rotação externa. Durante a fase subaquática o SA se mantém ativo e estabiliza a escápula na caixa torácica, enquanto o grande dorsal e peitoral maior geram a força propulsora. Dessa maneira o SA permanece ativo durante todo o ciclo de movimento estando mais propenso à fadiga (PINK et al., 1991a).

Um atleta pode realizar até 2500 braçadas em apenas um dia de treinamento o que o torna susceptível a fadiga (PINK; TIBONE, 2000). A fadiga resulta em alterações do controle motor por diminuir a capacidade de resposta muscular frente uma determinada tarefa, modificando o padrão de movimento (MACINTOSH; RASSIER, 2002). Especificamente no $\mathrm{CO}$, a fadiga propicia alteração da cinemática e assincronias entre as articulações GU e ET (CHANG et al., 2006; MCQUADE; SMIDT, 1998).

Em atletas de natação foi verificado que em situação de fadiga o padrão dos movimentos está inadequado e são necessárias estratégias compensatórias na tentativa de se manter o desempenho (STIRN et al., 2011). Segundo Madsen et al. (2011), 82\% dos atletas avaliados através de método observacional apresentaram discinese no último quarto de treinamento.

Estudos com avaliação tridimensional da articulação ET em situações de fadiga apresentam resultados variados. Chopp et al.(2011) e Joshi et al. (2011) realizaram protocolos de fadiga para o MR idênticos e encontraram resultados diferente com aumento e diminuição respectivamente da rotação superior da escápula. Adicionalmente, Chopp et al. (2011) realizou um protocolo de fadiga global para musculatura do ombro, e além do aumento da rotação superior encontro também aumento da inclinação posterior da escápula. 
Os efeitos da fadiga na atividade eletromiográfica foram estudados por Joshi et al. (2011). Após um protocolo especifico para o MR, houve diminuição da atividade do TD, sendo que o SA e TA não apresentaram diferença significativa no pós fadiga.

Os efeitos da fadiga na cinemática da articulação ET em atletas com SIS podem diferir de atletas assintomáticos. Su et al. (2004) avaliaram o posicionamento escapular bidimensional em repouso, $45^{\circ}, 90^{\circ}$ e $135^{\circ}$ com auxílio de inclinômetro, antes e após uma série de treinamento intenso de 2 horas. Foram divididos 2 grupos, um assintomático e outro com SIS. O grupo sintomático apresentou diminuição da rotação superior da escápula principalmente a $90^{\circ}$ de abdução. Segundo esses autores, os achados podem contribuir para a perpetuação do quadro clínico e parte do tratamento deve ser voltada para correção do posicionamento escapular destes atletas.

As evidências até o presente momento sobre a biomecânica tridimensional da articulação ET em nadadores em situações de fadiga são escassas. A partir disso, o presente estudo objetivou elucidar possíveis alterações na cinemática tridimensional da escápula e atividade eletromiográfica dos músculos trapézio ascendente, inferior, médio e serrátil anterior após um teste de esforço máximo. Trabalhamos com a hipótese que após a realização de um teste de esforço máximo, sejam observadas alterações cinemáticas na articulação ET e da atividade eletromiográfica incluindo diminuição da ativação do músculo SA.

\section{2-REVISÃO DA LITERATURA}

\section{1-Biomecânica da articulação ET}

\subsection{1-Cinemática}

Cinemática é o estudo dos movimentos sem a preocupação com as suas causas (HEWITT 2009). Dentro da biomecânica, variados estudos cinemáticos têm sido conduzidos com intuído de descrever padrões de movimento humanos normais e patológicos. Para padronização das pesquisas e melhor comparação entre os resultados, a International Society of Biomechanics (ISB) redigiu um guia com instruções para os pesquisadores (WU et al., 2005). Foram descritas orientações para criação dos sistemas de coordenadas locais (SCL) que são definidos através dos eixos do corpo e discriminam cada seguimento anatômico e seus centros articulares. Foram estabelecidas também sequências de rotações entre os seguimentos, para que os resultados apresentem sentido do ponto de vista clínico (WU et al., 2005). Desta maneira a movimentação de uma articulação pode ser descrita por rotações sucessivas em torno dos três eixos entre dois segmentos do SCL ou entre um segmento do 
SCL e o sistema de coordenadas global (SCG) referente ao ambiente de coleta (WU et al., 2005).

No caso de avaliações dos MMSS o SCG, o eixo X representa a direção ântero-posterior, o Y a direção vertical e o Z a direção latero-lateral (WU et al., 2005).

Análises cinemáticas tridimensionais da articulação ET foram realizadas em variadas tarefas, incluindo movimentos de elevação do ombro em diversos planos de elevação, tarefas funcionais e gestos esportivos como o arremesso do basebol e o forehand do tênis (LUDEWIG et al., 2009; MEYER et al., 2008; ROGOWSKI et al., 2014; RUNDQUIST; OBRECHT; WOODRUFF, 2009; SHEIKHZADEH et al., 2008). Para isso foram utilizados sistemas de rastreamento, destacando-se os eletromagnéticos e os com câmeras infravermelhas (CHU et al., 2012; HOARD et al., 2013; KARDUNA et al., 2001; ROY et al., 2007). Os sistemas com câmeras infravermelho apresentam a vantagem de maior liberdade de movimentos, visto que não são necessários fios conectados ao voluntário.

A avaliação da articulação ET pode apresentar limitações devido ao deslizamento da pele sobre a escápula durante os movimentos de elevação (LEMPEREUR et al., 2014). Para minimizar tal problema foram desenvolvidas técnicas utilizando-se clusters de marcadores posicionados na região do acrômio. A técnica com o cluster consiste em posicionar sobre a face plana do acrômio, onde o deslizamento de pele é reduzido, um objeto rígido com no mínimo três marcadores reflexivos não lineares. São necessárias inicialmente coletas estáticas, as quais informam o posicionamento da escápula em relação ao cluster acromial. A partir disso, cálculos matemáticos de referência conseguem discriminar o posicionamento da escápula durante o movimento, sem a necessidade de marcadores específicos em suas proeminências ósseas, levando-se em consideração o posicionamento do cluster (KARDUNA et al., 2001; WARNER; CHAPPELL; STOKES, 2015). Dessa maneira, erros na aferição da cinemática da articulação ET foram minimizados em angulações abaixo dos $120^{\circ}$ de elevação (LEMPEREUR et al., 2014).

Os movimentos da articulação ET são realizados em três planos: rotação superior/inferior ao redor do eixo perpendicular ao plano da escápula, rotação interna/externa ao redor do eixo vertical do tronco e a inclinação anterior/posterior realizada no eixo horizontal a espinha da escápula. De acordo com a ação realizada pelo membro superior, cada um ocorre em maior ou menor magnitude. Durante a elevação do ombro, são realizados movimentos simultâneos de rotação superior e inclinação posterior. A rotação interna e externa varia de acordo com o plano e fase do movimento (LUDEWIG et al., 2009; MCCLURE et al., 2001). 


\subsection{2-Atividade muscular}

Para adequada movimentação da articulação ET o sinergismo dos músculos periescapulares é essencial. Eles devem atuar de maneira coordenada formando pares de força, o que gera o deslizamento da escápula sobre a caixa torácica e direciona a articulação GU por toda a ADM (PHADKE; CAMARGO; LUDEWIG, 2009).

Durante o movimento de elevação dos MMSS, o TA e o SA são os principais músculos responsáveis pela rotação superior da escápula e se observa aumento da atividade eletromiográfica conforme se eleva o ângulo do movimento (EKSTROM et al., 2004; LUDEWIG; COOK; NAWOCZENSKI, 1996). O TA apresenta atividade muscular antecipatória aos movimentos de elevação do ombro e permanece ativo por toda a ADM. O SA, devido à inserção na borda medial e ângulo inferior da escápula, adicionalmente realiza a inclinação posterior e rotação externa da escápula (LUDEWIG; COOK; NAWOCZENSKI, 1996). É observado ainda que o SA se mantém ativado desde o início do movimento, tendo um papel importante na estabilização da escápula na parede torácica nos ângulos iniciais, e realizando a rotação superior da escápula principalmente a partir dos $60^{\circ}$ de elevação do úmero (WADSWORTH; BULLOCK-SAXTON, 1997).

$\mathrm{O}$ TD em razão à orientação de suas fibras colabora com a rotação superior e atua principalmente na rotação externa e inclinação posterior da escápula. A ativação do TD iniciase próximo aos $15^{\circ}$ de elevação do ombro e se contrapõem ao movimento de protração escapular gerado pelo SA, desta maneira mantém o centro de rotação da escápula relativamente inalterado durante $\mathrm{o}$ início do movimento de elevação do ombro (WADSWORTH; BULLOCK-SAXTON, 1997). O Trapézio transverso (TT) estabiliza a borda medial da escápula, realiza rotação externa e apresenta ativação durante toda a ADM (LUDEWIG; COOK; NAWOCZENSKI, 1996; PHADKE; CAMARGO; LUDEWIG, 2009).

\section{2-Alterações da biomecânica da articulação ET}

\subsection{1-Cinemática}

Alterações visíveis do posicionamento em repouso e da movimentação escapular são descritos como discinese escapular (KIBLER et al., 2013). Em geral refletem uma diminuição do controle neuromuscular da articulação ET (WARNER et al., 2013).

Foram propostas diversas classificações para se verificar a presença da discinese escapular. Kibler et al. (2013) desenvolveram uma classificação de I a IV sem especificar a gravidade da disfunção. A avaliação consiste em observar o posicionamento escapular em repouso e durante o movimento de elevação e abaixamento dos membros superiores. No 
padrão tipo I, o ângulo inferior da escápula encontra-se proeminente durante o movimento, o acrômio inclina-se anteriormente e o ângulo inferior inclina-se posteriormente. No tipo II a borda medial da escápula está proeminente no repouso e durante o movimento. No tipo III, a borda superior da escápula permanece elevada no repouso e durante o movimento não é observada a inclinação posterior. O tipo IV é considerado normal, com uma posição simétrica, na qual não se observa excessiva movimentação (KIBLER et al., 2013).

A discinese preferencialmente deve ser avaliada na fase descendente do movimento, pois as alterações musculares e cinemáticas são evidenciadas na contração excêntrica (CHOPP-HURLEY et al., 2016; HUANG et al., 2015). O acréscimo de carga facilita a análise, visto que dessa maneira a ativação dos músculos escapulares está aumentada e consequentemente alterações podem ser observadas com maior clareza (REED et al., 2016).

Diversos fatores podem influenciar no aparecimento da discinese escapular (KIBLER et al., 2013), incluindo fraqueza ou paralisia muscular, diminuição do controle neuromuscular e alterações na extensibilidade de tecidos moles.

Em atletas que realizam o gesto esportivo com movimentos acima da linha da cabeça, a cápsula posterior da art. GU pode sofrer alterações anatômicas e ficar encurtada. Por ser inserida na região posterior da cavidade glenóide, essa alteração proporciona aumento da rotação interna da escápula, além de alterar o posicionamento do centro de rotação da cabeça do úmero na articulação GU (DASHOTTAR; BORSTAD, 2012).

O músculo peitoral menor tem origem na face anterior da $3^{\circ}, 4^{\circ}$ e $5^{\circ}$ costelas e se insere no processo coracóide da escápula. Sujeitos com encurtamento desse músculo apresentam aumento da rotação interna e redução da inclinação posterior da escápula durante elevação do ombro (BORSTAD; LUDEWIG, 2005; MORAIS; CRUZ, 2016).

Em nadadores, durante a fase aérea da braçada a escápula deve estar inclinada posteriormente e rodada externamente para favorecer a rotação externa da articulação GU (HEINLEIN; COSGAREA, 2010). Assim os encurtamentos do peitoral menor e da cápsula posterior do ombro restringem os movimentos da escapular, sobrecarregando a articulação glenoumeral durante o gesto esportivo (MORAIS; CRUZ, 2016).

\subsection{2-Atividade muscular}

A escápula é base para inserção dos principais músculos tanto da articulação GU quanto da ET (TERRY; CHOPP, 2000). O padrão de recrutamento muscular da escápula em situações patológicas apresenta grande variabilidade entre sujeitos (LUDEWING; COOK, 2000; STRUYF et al., 2014; TUCKER et al., 2010). Desta maneira o funcionamento 
adequado do CO pode ser afetado. Dentre as principais alterações estão o aumento da ativação muscular do TA e diminuição da ativação do SA (LUDEWING; COOK, 2000; SOUSA et al., 2015). Além disso, resultados conflitantes em relação ao TD demonstraram aumento de atividade eletromiográfica como no estudo de (LUDEWING; COOK, 2000)Ludewig; Cook (2000) e diminuição da atividade eletromiográfica como no estudo de Shinohara et al. (2014).

Alterações da atividade muscular também são encontradas em sujeitos assintomáticos com discinese escapular. Huang et al. (2015) encontraram aumento da ativação de TA e diminuição da ativação muscular do TD e SA durante a fase descendente do movimento do ombro no plano da escápula. Tais achados podem ser comparados aos encontrados em voluntários com síndrome do impacto (SIS) (LUDEWING; COOK, 2000; STRUYF et al., 2014). 


\section{3- OBJETIVO GERAL}

Comparar as rotações da articulação escapulotorácica e amplitude eletromiográfica da cintura escapular em nadadores antes e após a realização de um teste de esforço máximo com duração de 3 minutos.

\section{1- Objetivos específicos:}

- Verificar a cinemática tridimensional da cintura escapular, durante o movimento de elevação no plano da escápula, contemplando a rotação superior/inferior, rotação medial/lateral e inclinação anterior/posterior de nadadores antes e após a realização de um teste de esforço máximo de 3 minutos.

- Verificar a atividade eletromiográfica dos músculos TD, TT, TA e SA durante a fase descendente do movimento no plano da escápula de nadadores antes e após a realização de um teste de esforço máximo de 3 minutos.

- Analisar como a variação da atividade muscular após a realização de um teste de esforço máximo de 3 minutos pode influenciar a cinemática escapular dos nadadores. 


\section{4- MATERIAIS E MÉTODOS}

\section{1- Aspectos éticos}

O presente estudo foi aprovado pelo comitê de ética e pesquisa da Escola de Educação Física e Esporte de Ribeirão Preto (EEFERP-USP). Todos os voluntários ou seus representantes legais, em caso de menores de dezoito anos, previamente assinaram ao TCLM número 44107014.7.0000.5659 contendo informações referentes aos testes realizados, seus riscos e benefícios, o local de realização e o contato dos responsáveis.

\section{2- Caracterização da amostra}

Foram convidados para o estudo 16 atletas do sexo masculino na faixa etária de 15 a 24 anos. O recrutamento foi realizado em equipes de natação da região de Ribeirão Preto-SP e em Associações Atléticas Estudantis da USP. Os atletas participavam de competições em nível universitário, estadual e/ou nacional.

Os estilos de nados para treinamentos e competições foram o livre e o borboleta, nas distâncias de 50m, 100m, 200m e 800m.

Os dados antropométricos, idade, tempo de prática, horas de treinamento por semana estão na tabela 1 em forma de média (MED) e desvio padrão (DP).

Tabela 1- Características dos participantes

\begin{tabular}{ll}
\hline Idade (anos) & $18,6 \pm 4,1$ \\
Peso (Kg) & $71 \pm 9,5$ \\
Altura (m) & $1,78 \pm 4,1$ \\
Tempo de prática (anos) & $7,3 \pm 3,1$ \\
$\begin{array}{l}\text { Horas de treinamento por } \\
\text { semana (h) }\end{array}$ & $11,6 \pm 3,8$ \\
\hline
\end{tabular}

Resultados: média \pm desvio padrão.

\section{3- Critérios de inclusão}

Foram incluídos no estudo voluntários que apresentavam os seguintes critérios: Mínimo de dois anos de prática de natação, mínimo de 7 horas de treinamento por semana e disputar competições em nível estadual ou nacional. 


\section{4- Critérios de Exclusão}

Foram excluídos os voluntários que apresentaram as seguintes características: Amplitude dos movimentos de elevação do ombro menor que $150^{\circ}$, avaliada visualmente; cirurgias no ombro; presença de deformidade grave visível na coluna torácica como escoliose ou hipercifose, devido à possível alteração dos movimentos da escápula; dor irradiada no ombro ou parestesia no membro superior, por serem indicativos de comprometimento da coluna cervical (LEITE, FALOPPA 2013); doenças que acometam as articulações de forma sistêmica, por exemplo, a artrite reumatóide; dor no ombro (EVA > 3) ou apresentar sinais clínicos de SIS, considerando quando encontrado em pelo menos 2 dos seguintes teste: Neer, Hawkins-Kennedy e Arco doloroso (LEITE, FALOPPA 2013).

\section{5- Instrumentação}

Os procedimentos foram realizados no Laboratório de Biomecânica e Controle Motor (LaBioCoM) da EEFERP-USP.

\subsection{1- Cinemática}

Foi utilizado o Sistema VICON (Contennial, CO, EUA), composto de oito câmeras MX-T-40S com quatro megapixels de resolução espacial e 120 quadros por segundos de resolução temporal, para a obtenção das coordenadas tridimensionais dos marcadores reflexivos. Os dados tridimensionais de cada marcador foram exportados do software NEXUS® 1.8 em formato .C3D para posterior processamento.

\subsection{2- Eletromiografia (EMG)}

O sistema utilizado foi o EMG Trigno ${ }^{\mathrm{TM}}$ Wireless System (Delsys ${ }^{\circledR}$, Inc., Boston, Massachusetts, EUA), composto por 16 canais, de 16 bits de resolução, com frequência de aquisição de $2.000 \mathrm{~Hz}$. Os sensores de superfície eram bipolares, sem fio, em formato de barra paralela (tamanho: $37 \mathrm{~mm}$ x $26 \mathrm{~mm}$ x $15 \mathrm{~mm}$ ) e com distância fixa de 1,0 cm, o que diminui a variabilidade temporal e de amplitude das medidas. Tal aparelho permite a sincronização do sinal junto à cinemática através do software NEXUS® 1.8 . 


\section{6- Procedimentos}

A Figura-1 representa um fluxograma dos procedimentos realizados. Inicialmente os voluntários passaram por uma entrevista para coleta de dados pessoais, histórico de lesões e medidas antropométricas.

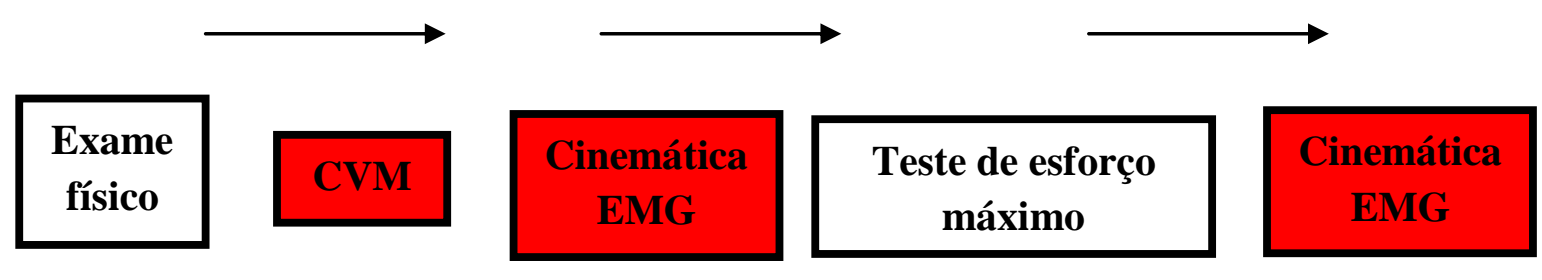

Figura 1: Fluxograma dos procedimentos

\subsection{1- Cinemática}

\subsubsection{1-Sistemas de coordenadas}

Inicialmente foi construído o sistema de coordenadas globais usando-se o laboratório como referência e a partir disso foram definidos os eixos: $\mathrm{X}$ sentido antero-posterior, $\mathrm{Y}$ médio-lateral e o Z vertical.

Um sistema de coordenadas locais foi estabelecido seguindo as especificações da ISB (WU et al., 2005). Foram definidos os seguimentos tórax, escápula e úmero. Eles foram montados através dos seguintes pontos anatômicos: Tórax- Processo xifóide (PX), incisura jugular (IJ), processo espinho de C7 (PE C-7), processo espinhos de T8 (PE T-8); Escápulatrígono da escápula (TRE), ângulo acromial (AA), ângulo inferior da escápula (AIE) e Úmero- centro de rotação glenoumeral (CRGU), epicôndilo lateral (EL) e epicôndilo medial (EM) do úmero. O CRGU foi obtido através do método de regressão proposto Veeger (2000).

\subsubsection{2-Cluster e tomada estática}

Com intuito de aprimorar os resultados da cinemática da articulação ET foi utilizado o método Acromion Marker Cluster (AMC). Esse método tem o objetivo de minimizar os efeitos do deslizamento de pele sobre a escápula e apresenta boa confiabilidade para medidas abaixo de $120^{\circ}$ de elevação do úmero (WARNER; CHAPPELL; STOKES, 2012). O cluster é formado por uma estrutura rígida em L com 3 marcadores, formando um plano e está posicionado na porção lateral e posterior do acrômio, com um de seus braços seguindo a orientação da espinha da escápula. A Figura-2 ilustra o posicionamento do AMC e dos marcadores do tronco. Adicionalmente foi colocado outro cluster com quatro marcadores na 
região lateral do úmero para auxílio do rastreamento do braço denominado Humero Marker Cluster (HMC). A partir disso e considerando que cada segmento é rígido e independente, as posições relativas de cada conjunto não variam entre os segmentos. Portanto, é possível descrever matematicamente a posição de cada segmento em um sistema de referência.
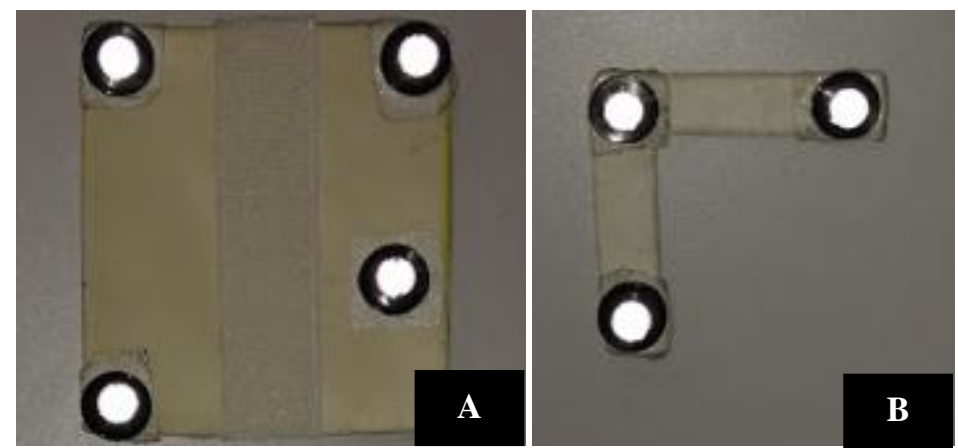

Figura-2: Clusters utilizados para realização da cinemática tridimensional da escápula. $\mathrm{A}=$ Humero marker cluster $(\mathrm{HMC}), \mathrm{B}=$ Acromion marker cluster (AMC).

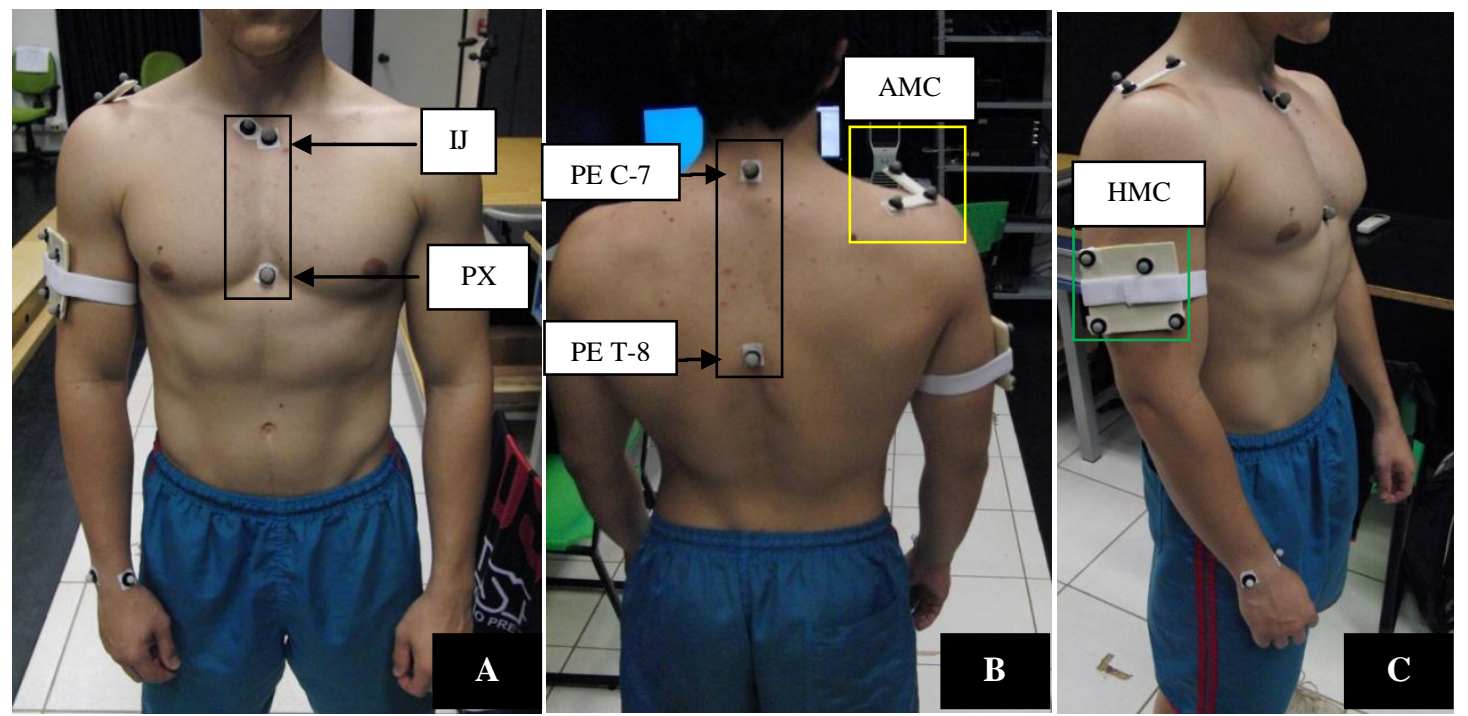

Figura-3: Posicionamentos dos marcadores do tórax, dos clusters da escápula e do úmero.

$\mathrm{A}=$ marcadores anteriores do tórax: Incisura jugular (IJ), processo xifóide (PX); $\mathrm{B}=$ Acromion marker cluster (AMC) e marcadores posteriores do tórax: processo espinhoso de C-7 e processo espinhoso de $\mathrm{T}-8 ; \mathrm{C}=$ Humero marker cluster $(\mathrm{HMC})$.

\subsubsection{3-Calibração e tomadas estáticas}

Foram posicionados marcadores reflexivos no tórax (PX, IJ, PE C-7 e PE T-8) e 2 clusters no acrômio e úmero. Os pontos anatômicos da escápula e do úmero foram encontrados com auxílio de um bastão com 4 marcadores acoplados e com distâncias previamente conhecidas (figura 3). Inicialmente são realizadas aquisições estáticas com o 
sujeito na posição anatômica durante 3 segundos, estando o bastão posicionado com uma de suas pontas sobre um ponto anatômico. Tal procedimento foi repetido com o bastão posicionado em cada um dos pontos da escápula (AA, AIE, TE) e do úmero (EM, EL). A partir disso é possível descrever matematicamente a posição de cada segmento em um sistema de referência entre o AMC e os pontos da escápula e o HMC e pontos do úmero.

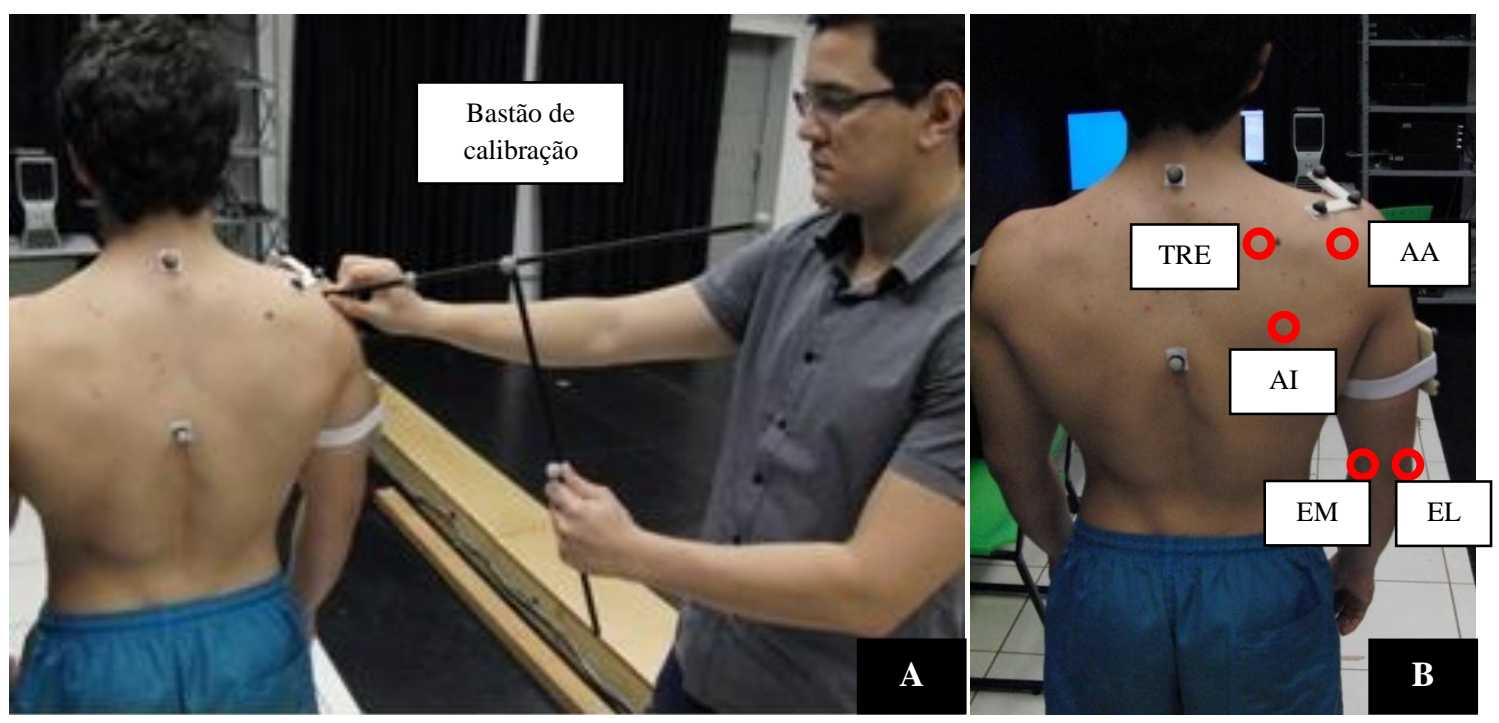

Figura-4: $\mathrm{A}=$ Posicionamento do bastão de calibração no AA. B= círculos vermelhos representam os 5 pontos anatômicos discriminados durante a calibração.

\subsubsection{4-Tomadas dinâmicas}

Os testes dinâmicos foram realizados na posição ortostática com os MMSS em posição anatômica inicialmente. Foi solicitado aos voluntários que realizassem três repetições elevação no plano da escápula mantendo o polegar direcionado para cima, evitando rotações do braço. O plano da escápula foi definido como $40^{\circ}$ anterior ao plano coronal. Linhas traçadas no chão serviram de orientação para correta movimentação dos voluntários. Os movimentos tiveram a duração de 4 segundos (KARDUNA et al., 2001), sendo 2 segundos para subida e 2 segundos para descida, com o pesquisador fornecendo feedback verbal para controle do tempo. Foi utilizado um halter de $1 \mathrm{~kg}$ em cada uma das mãos dos voluntários durante a movimentação (REED et al., 2016).

\subsection{2- Eletromiografia}

Previamente a aquisição dos dados a pele do local a ser avaliado foi preparada realizando-se tricotomia e limpeza do local com álcool 70\%.

Foram analisados os músculos: TA, TT, TD e SA (figura-5). 
Para o músculo TA, o sensor foi posicionado no ponto médio de uma reta traçada entre o processo espinhoso da sétima vértebra cervical ao AA (HERMENS et al., 1999).

O TD teve o sensor posicionado a 2/3 de uma linha traçada entre o trígono escapular e a $8^{\circ}$ vértebra torácica (HERMENS et al., 1999).

O TT foi posicionado no ponto médio entre a borda medial da escápula e o processo espinhoso de T3 (HERMENS et al., 1999).

Para o SA, o sensor foi posicionado anterior às fibras do grande dorsal no sétimo espaço intercostal com o ombro abduzido a 90 (EKSTROM; SODERBERG; DONATELLI, 2005).

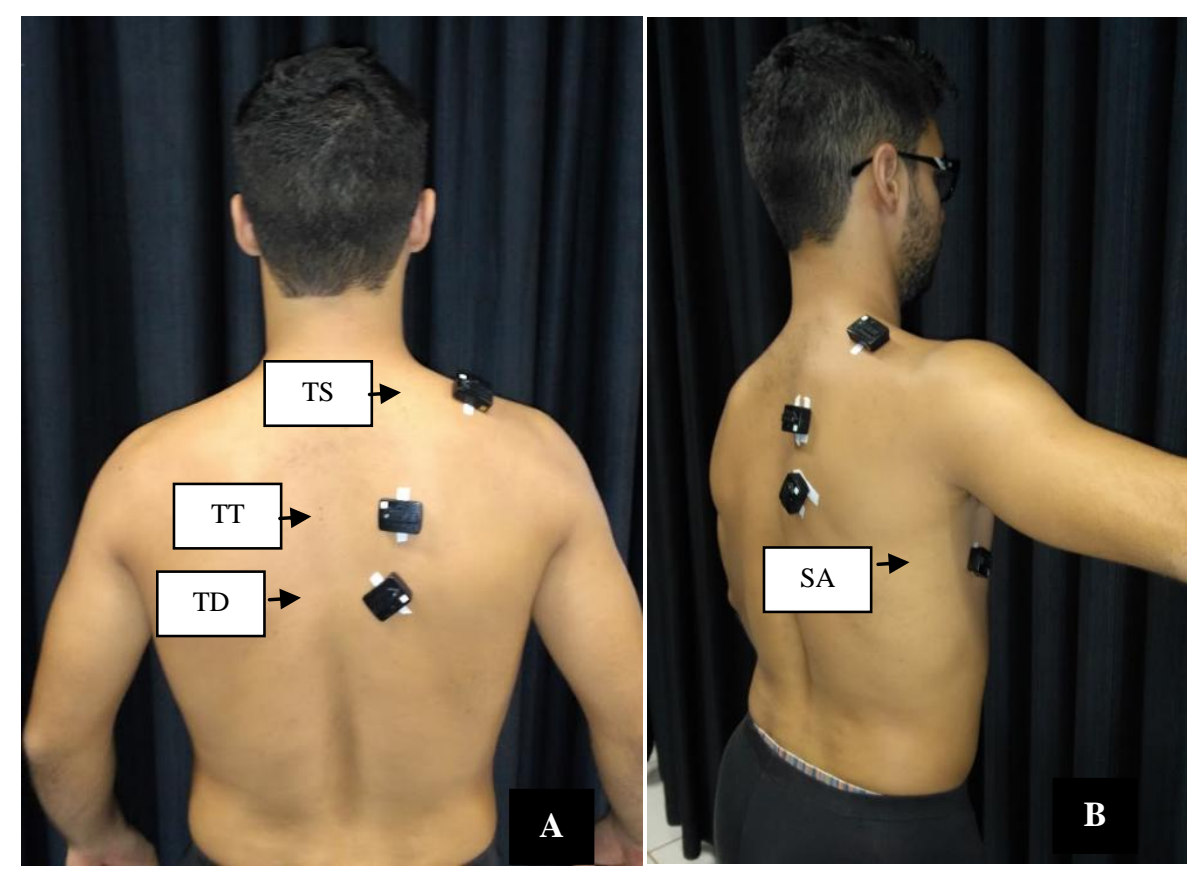

Figura-5: Posicionamento dos eletromiógrafos. A= Trapézio ascendente (TS), trapézio transverso (TT) e trapézio descendente $(\mathrm{TI})$. $\mathrm{B}=$ Serrátil anterior $(\mathrm{SA})$.

\subsection{3- Contração voluntária máxima (CVM)}

A realização da CVM teve o intuito de posterior normalização dos dados da eletromiografia. Foram feitas três tentativas para cada um dos músculos. As contrações foram realizadas durante 5 segundos e o intervalo de descanso foi de 60 segundos. $\mathrm{O}$ valor final da CVM foi encontrado a partir da média das três tentativas realizadas. Previamente foram realizadas duas coletas em cada posição para familiarização dos voluntários com os testes.

Para o músculo TD o posicionamento adotado foi em decúbito ventral, com abdução de $120^{\circ}$ e rotação externa. A resistência foi aplicada na região distal do antebraço (EKSTROM; SODERBERG; DONATELLI, 2005). 
O TT foi analisado em decúbito ventral com $90^{\circ}$ de abdução de ombro. A resistência foi aplicada na região distal do antebraço (EKSTROM; SODERBERG; DONATELLI, 2005).

O SA foi analisado com o voluntário sentado, o ombro em $120^{\circ}$ de elevação no plano da escápula e rotação neutra. A resistência foi aplicada na região distal do antebraço (SCHÜLDT et al. 1988).

O TA foi analisado com o voluntário sentado e o ombro em abdução de $90^{\circ}$ e rotação neutra. A resistência foi aplicada na região distal do antebraço (MCLEAN et al., 2003).

\section{7- Teste de esforço máximo}

O teste teve a finalidade de verificar a capacidade máxima dos voluntários durante três minutos numa tarefa exaustiva. Para execução desta tarefa foi utilizado um banco de natação (Figura-6), procurando aproximar-se ao gesto esportivo. Os marcadores reflexivos posicionados na região anterior do tórax foram retirados durante o teste para maior conforto. Marcações foram realizadas na pele para a recolocação dos marcadores no mesmo local após seu término para realização da coleta de dados subsequente ao teste.

Para realização do teste foram utilizados dois palmares presos a uma resistência elástica (auriflex 14mm de média resistência) e acoplados a uma estrutura fixa para simular a carga exercida sobre os MMSS durante as braçadas. Inicialmente os atletas foram instruídos a realizar o movimento do teste para familiarização. Durante todo o protocolo, os voluntários foram encorajados através de estímulo verbal a manter a movimentação do ombro simulando as braçadas em intensidade máxima durante 3 minutos. A figura- 6 a seguir demonstra o movimento realizado. 

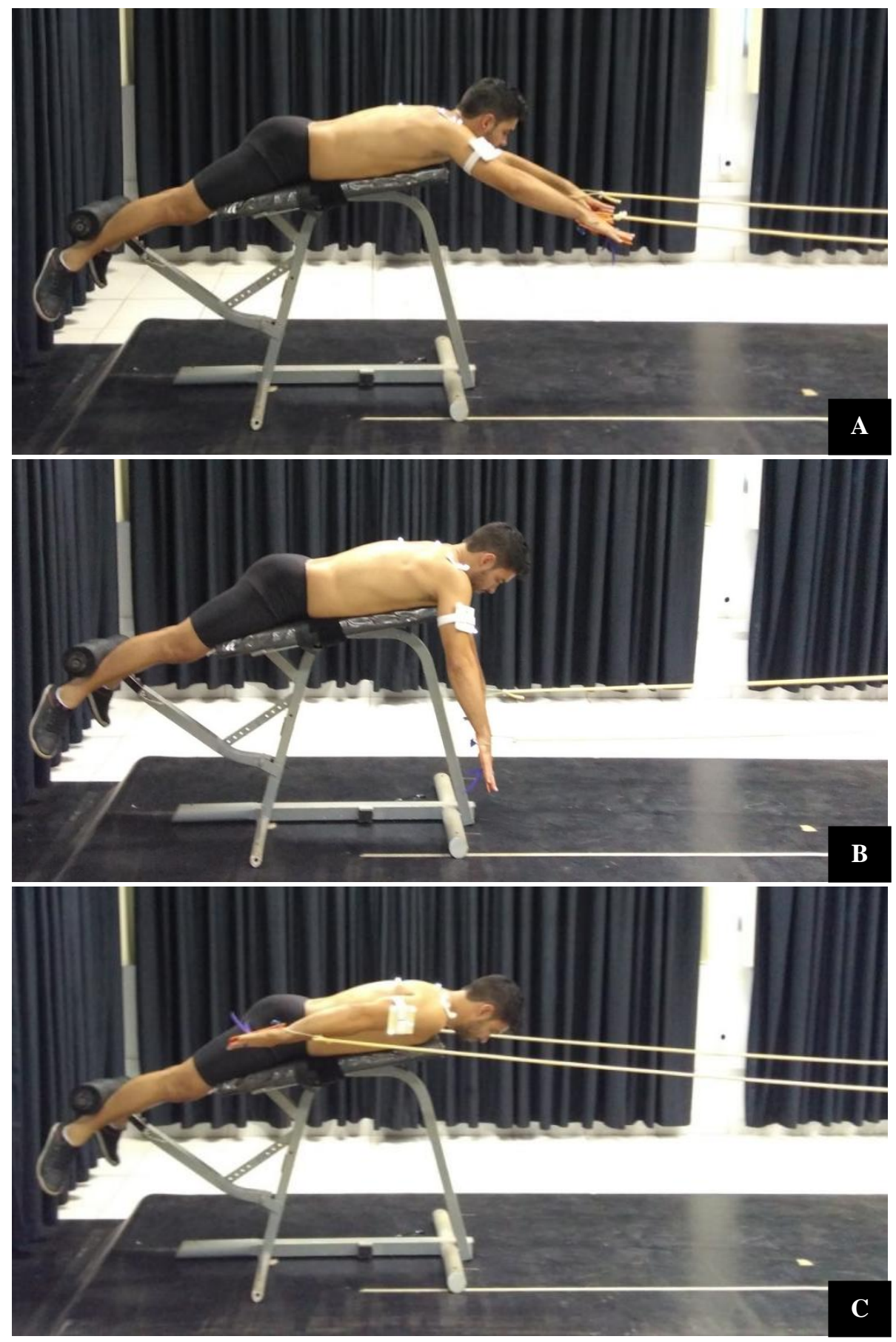

Figura-6: Teste de esforço máximo de 3 minutos. A=posição inicial, $B=$ posição média e $C=$ posição final. 


\section{5- Análise dos dados}

\section{1- Cinemática}

Os movimentos foram analisados entres os seguimentos do úmero em relação ao tórax e da escápula em relação ao tórax. A orientação do úmero em relação ao tórax seguiu a ordem XZY, com intuído de evitar a ocorrência de Gimbal lock. O eixo X representa os movimentos de abdução/adução, o Z de flexão/extensão e o Y de rotação interna/externa (PHADKE et al., 2011).

A orientação da escápula em relação ao tórax foi descrita usando a sequência de Euler YXZ. Rotação interna/externa ao redor do eixo vertical do tronco, rotação superior/inferior ao redor do eixo perpendicular ao plano da escapula e inclinação anterior/posterior através do eixo horizontal a espinha da escápula respectivamente (WU et al., 2005).

Os dados inicialmente foram processados no software NEXUS® 1.8 para aplicação de modelo biomecânico e filtrados com o buterworth de $4^{\circ}$ ordem com intuito de eliminar possíveis ruídos da coleta. Posteriormente os dados foram exportados na forma de arquivos .C3D. Em seguida, usando o aplicativo ShoulderModel (figura 5) foram calculados os valores angulares de rotação da escápula em relação ao tórax a partir dos arquivos em .C3D. Tal aplicativo foi desenvolvido no Software MatLab (Mathworks Inc. Natick, MA, USA) e disponibilizado em parceria firmada com o pesquisador Martin B. Warner da University of Southampton. A partir disso, foi utilizado o Software MatLab 2014a (Mathworks Inc. Natick, $M A, U S A)$ para selecionar e extrair os dados relativos à angulação de repouso, $30^{\circ}, 60^{\circ}, 90^{\circ}$, $120^{\circ}$ nas fases ascendente e descendentes do movimento de elevação do úmero.

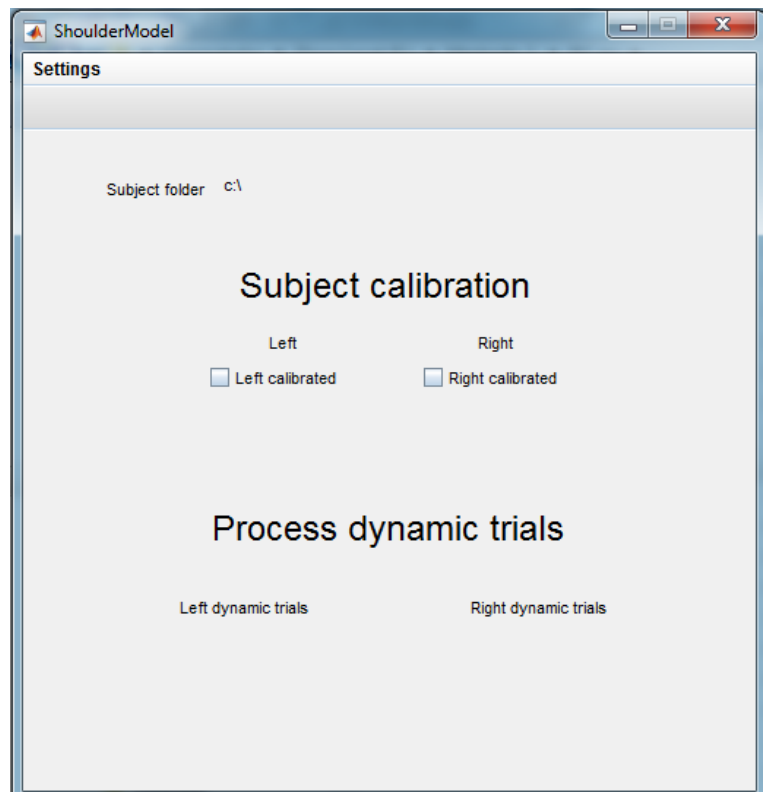

Figura-7: Tela inicial do aplicativo ShoulderModel 


\section{2- Eletromiografia}

Os sinais eletromiográficos foram amostrados em $2.000 \mathrm{~Hz}$, com um ganho de 1.000 e filtrados com um Butterworth de $4^{\circ}$ ordem a uma frequência passa-banda de 20-450 Hz.

A atividade muscular foi determinada para cada tentativa na fase descendente do movimento a partir das janelas de $120^{\circ}-90^{\circ}, 90^{\circ}-60$ e $60^{\circ}-30^{\circ}$ do movimento do braço. Foi optado pela parte descendente do movimento devido à maior atividade muscular observada na fase excêntrica (HUANG et al., 2015; LUDEWIG; COOK; NAWOCZENSKI, 1996). Após a separação, os dados foram suavizados utilizando-se um algoritmo de Raiz Quadrada da Média (RMS) com tamanho de janela de $0.125 \mathrm{~ms}$ e sobreposição de $0.0625 \mathrm{~ms}$. Por fim, para normalização dos dados eletromiográficos, os resultados foram divididos pelo máximo valor registrado na CVM, multiplicados por 100 e referidos como porcentagem. A partir dos resultados das três tentativas foram obtidas médias dos valores para cada um dos músculos. Todo o processamento do sinal eletromiográfico foi realizado com o Software MatLab 2014a (Mathworks Inc. Natick, MA, USA). 


\section{6- ANÁLISE ESTATÍSTICA}

A análise descritiva foi realizada como MED e erro padrão (EP) para todas as variáveis cinemáticas e eletromiográficas. O teste de Shapiro-Wilk foi utilizado para checar a normalidade dos dados. Verificadas as pressuposições de distribuição normal do modelo, as variáveis cinemáticas de rotação interna, rotação superior e inclinação anterior da escápula e a atividade eletromiográfica dos músculos TD, TA, SA, TT foram comparadas através de teste T para amostras pareadas para detecção de diferenças entre as situações pré e pós teste. As análises realizadas foram pareadas para cada um dos ângulos nas fases ascendentes e descendentes do movimento do braço (ascendente: repouso, $30^{\circ}, 60^{\circ}, 90^{\circ}, 120$; descendente: $120^{\circ}, 90,60^{\circ}, 30^{\circ}$ ) e para as variáveis eletromiográficas da fase descendente do movimento do braço $\left(120-90^{\circ}, 90^{\circ}-60^{\circ}, 60^{\circ}-30^{\circ}\right)$. Para todas as variáveis foi adotado nível de significância de $5 \%$.

O cálculo do tamanho do efeito (TE) foi realizado para cada uma das variáveis estudadas pelo cálculo do $d$ Cohen's. A fórmula utilizada para o cálculo foi: d=M1-M2/ DPpooled, a qual M1 é a média inicial, M2 a média final e DPpooled é o desvio padrão agrupado. Para o cálculo do desvio padrão agrupado: DPpooled $\left.=\sqrt{ }\left[\underline{\mathrm{Dp}} 1^{2}+\mathrm{DP} 2^{2}\right) / 2\right]$. O TE foi interpretado como pequeno $(<0,5)$, moderado $(>0,5$ a $<0,8)$ e grande $(>0,8)(\mathrm{COHEN}, 1992)$. Para todas as variáveis foi adotado nível de significância de $5 \%$.

Para analisar o poder explicativo da ativação muscular (VAM) na variação cinemática (VC) foram propostos 6 modelos de regressão linear simples: A: poder explicativo da VAM do TT $120^{\circ}-90^{\circ}$ sobre a VC da inclinação anterior à $90^{\circ}$; B: poder explicativo da VAM do TD $60^{\circ}-30^{\circ}$ sobre a VC da inclinação anterior a $60^{\circ}$; C: poder explicativo da VAM do TT $120^{\circ}-$ $90^{\circ}$ sobre a $\mathrm{VC}$ da rotação interna à $120^{\circ}$; D: poder explicativo da $\mathrm{VAM}$ do $\mathrm{TT} 120^{\circ}-90^{\circ}$ sobre a VC da rotação interna à $90^{\circ}$; E: poder explicativo da $\mathrm{VAM}$ do $\mathrm{TT} 60^{\circ}-30^{\circ}$ sobre a $\mathrm{VC}$ da rotação interna à $60^{\circ}$; e F: poder explicativo da VAM do TT $60^{\circ}-30^{\circ}$ sobre a $\mathrm{VC}$ da rotação interna à $30^{\circ}$. Os dados da regressão estavam em conformidade com os pressupostos da homocedasticidade, distribuição normal dos resíduos e não multicolinearidade entre as variáveis independentes. 


\section{7- RESULTADOS}

\section{1- Cinemática}

\subsection{1- Rotação interna da escápula}

Os dados cinemáticos relativos à rotação interna da escápula em cada uma das angulações analisadas durante as fases ascendentes e descendentes do movimento do braço antes e após a realização do teste de esforço máximo estão apresentados na tabela-2. Os valores estão em forma de MED, EP, diferença entre o pré e pós teste, intervalo de confiança (IC) da diferença, valor de $p$ e TE. Em todas as angulações analisadas foram encontradas diferenças estatisticamente significativas, porém com TE pequenos. A figura 8 ilustra os dados da rotação interna da escápula pré e pós-teste nas angulações de $30^{\circ}, 60^{\circ}, 90^{\circ}$ e 120 da fase ascendente do movimento e $120^{\circ}, 90^{\circ}, 60^{\circ}, 30^{\circ}$ da fase descendente do movimento do braço.

Tabela-2: Rotação interna da escápula. Valores negativos indicam rotação externa da escápula. No caso da diferença entre o pré e pós teste os valores negativos são referentes ao aumento da rotação interna no pós-teste.

\begin{tabular}{|c|c|c|c|c|c|c|c|}
\hline Variável & $\left({ }^{\circ}\right)$ & $\begin{array}{c}\text { Média pré (EP) } \\
\left({ }^{\circ}\right)\end{array}$ & $\begin{array}{c}\text { Média pós (EP) } \\
\left(^{\circ}\right)\end{array}$ & Dif. $\left({ }^{\circ}\right)$ & IC $95 \%$ & $P$ valor & TE \\
\hline \multirow{9}{*}{$\begin{array}{c}\text { Rot. } \\
\text { interna }\end{array}$} & Rep & $26,35( \pm 1,8)$ & $28,54( \pm 1,9)$ & $-2,19$ & $(-3.87 /-0,50)$ & $0,01^{*}$ & 0,36 \\
\hline & 30 & $27,75( \pm 2,1)$ & $29,92( \pm 2,2)$ & $-2,18$ & $(-3,79 /-0,55)$ & $0,01^{*}$ & 0,26 \\
\hline & 60 & $28,69( \pm 2,1)$ & $30,47( \pm 2,2)$ & $-1,78$ & $(-3,45 /-0,10)$ & $0,04^{*}$ & 0,20 \\
\hline & 90 & $29,33( \pm 2,3)$ & $31,28( \pm 2,3)$ & $-1,95$ & $(-3,75 /-0,13)$ & $0,04^{*}$ & 0,21 \\
\hline & 120 & $29,15( \pm 2,4)$ & $31,42( \pm 2,3)$ & $-2,27$ & $(-4,58 / 0,04)$ & $0,05^{*}$ & 0,24 \\
\hline & 120 & $28,38( \pm 2,1)$ & $30,83( \pm 2)$ & $-2,45$ & $(-4,67 /-0,22)$ & $0,03 *$ & 0,29 \\
\hline & 90 & $28,12( \pm 1,9)$ & $30,47( \pm 2)$ & $-2,35$ & $(-4,19 /-0,51)$ & $0,02 *$ & 0,29 \\
\hline & 60 & $27,12( \pm 1,9)$ & $29,92( \pm 2,1)$ & $-2,79$ & $(-4,36 /-1,22)$ & $0,01 *$ & 0,35 \\
\hline & 30 & $26,24( \pm 2)$ & $28,95( \pm 2,3)$ & $-2,71$ & $(-4,50 /-0,91)$ & $0,01 *$ & 0,32 \\
\hline
\end{tabular}

Rep: repouso Dif: diferença; EP: erro padrão; IC: intervalo de confiança da diferença. * p $<0,05$.

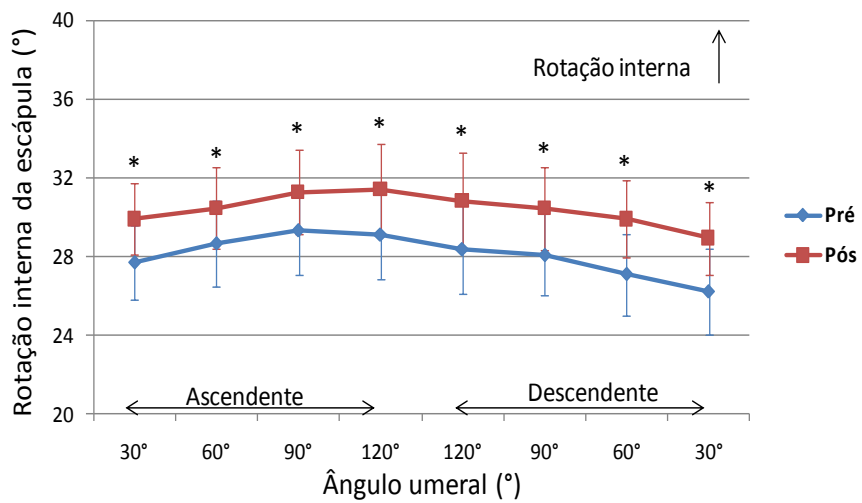

Figura 8: Medidas angulares do movimento de rotação interna/externa da escápula em relação ao tórax durante o movimento de elevação e abaixamento do braço no plano da escápula. 


\subsection{2-Rotação superior da escápula}

Os dados cinemáticos relativos à rotação superior da escápula em cada uma das angulações analisadas durante as fases ascendentes e descendentes do movimento do braço antes e após a realização do teste de esforço máximo estão apresentados na tabela-3. Os valores estão em forma de MED e EP, diferença entre o pré e pós teste IC da diferença, valor de $p$ e TE. Foi encontrada diferença estatisticamente significativa da angulação em repouso ( $\mathrm{p}=0,01)$ e TE pequeno $(d=0,47)$. A figura 9 ilustra os dados da rotação superior da escápula pré e pós-teste nas angulações de $30^{\circ}, 60^{\circ}, 90^{\circ}$ e 120 da fase ascendente do movimento e $120^{\circ}, 90^{\circ}, 60^{\circ}, 30^{\circ}$ da fase descendente do movimento do braço.

\begin{tabular}{|c|c|c|c|c|c|c|c|}
\hline Variável & $\left({ }^{\circ}\right)$ & $\begin{array}{c}\text { Média pré (EP) } \\
\left(^{\circ}\right)\end{array}$ & $\begin{array}{c}\text { Média pós (EP) } \\
\left({ }^{\circ}\right)\end{array}$ & Dif. $\left(^{\circ}\right)$ & IC $95 \%$ & $P$ valor & TE \\
\hline 4 & $\operatorname{Rep}^{\circ}$ & $-3,48( \pm 1,1)$ & $-1,34( \pm 1,2)$ & 2,14 & $(-3,28 /-0,42)$ & $0,01^{*}$ & 0.47 \\
\hline & $30^{\circ}$ & $-6,82( \pm 1,2)$ & $-6,84( \pm 1,2)$ & 0,02 & $(-0,69 / 0,65)$ & 0,95 & 0,00 \\
\hline & $60^{\circ}$ & $-17,03( \pm 1,2)$ & $-17,08( \pm 1,2)$ & 0,05 & $(-0,87 / 0,77)$ & 0,89 & 0,00 \\
\hline Rot. & $90^{\circ}$ & $-25,70( \pm 1,2)$ & $-25,88( \pm 1,4)$ & 0,18 & $(-1,31 / 0,95)$ & 0,73 & 0,04 \\
\hline \multirow[t]{5}{*}{ Superior } & $120^{\circ}$ & $-33,83( \pm 1,2)$ & $-34,51( \pm 1,4)$ & 0,69 & $(-1,89 / 0,51)$ & 0,24 & 0,13 \\
\hline & $120^{\circ}$ & $-33,85( \pm 1,5)$ & $-34,62( \pm 1,6)$ & 0,76 & $(-2,12 / 0,59)$ & 0,25 & 0,13 \\
\hline & $90^{\circ}$ & $-25,14( \pm 1,4)$ & $-25,17( \pm 1,5)$ & 0,03 & $(-0,98 / 0,92)$ & 0,94 & 0,01 \\
\hline & $60^{\circ}$ & $-15,45( \pm 1,5)$ & $-15,62( \pm 1,7)$ & 0,17 & $(-1,20 / 0,87)$ & 0,73 & 0,03 \\
\hline & $30^{\circ}$ & $-4,62( \pm 1,4)$ & $-5,08( \pm 1,6)$ & 0,46 & $(-1,45 / 0,54)$ & 0,35 & 0,08 \\
\hline
\end{tabular}

Rep: repouso Dif: diferença; EP: erro padrão; IC: intervalo de confiança da diferença. * p < 0,05.

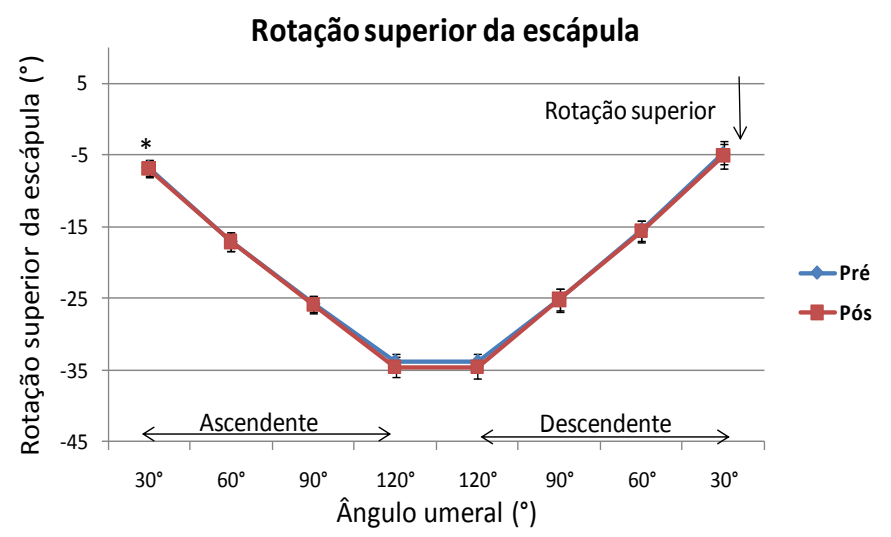

Figura 9: Medidas angulares do movimento de rotação superior da escápula em relação ao tórax durante o movimento de elevação e abaixamento do braço no plano da escápula. 


\subsection{3-Inclinação anterior/posterior da escápula}

Os dados cinemáticos relativos à inclinação anterior/posterior da escápula em cada uma das angulações analisadas durante as fases ascendentes e descendentes do movimento do braço antes e após a realização do teste de esforço máximo estão apresentados na tabela-4. Os valores estão em forma de MED e EP, diferença entre o pré e pós teste, IC da diferença, valor de $p$ e TE. Foram encontradas diferenças estatisticamente significativas na angulação de $120^{\circ}$ nas fases ascendentes e descendentes $(\mathrm{p}=0,04 ; \mathrm{p}=0,04)$, ambas com TE pequeno $(d=0,22$; $d=0,32$ ). A figura 10 ilustra os dados da rotação interna da escápula pré e pós-teste nas angulações de $30^{\circ}, 60^{\circ}, 90^{\circ}$ e 120 da fase ascendente do movimento e $120^{\circ}, 90^{\circ}, 60^{\circ}, 30^{\circ}$ da fase descendente do movimento do braço.

Tabela-4: Inclinação anterior/posterior da escápula. Valores negativos indicam inclinação anterior da escápula. No caso da diferença entre o pré e pós teste os valores são referentes ao aumento da inclinação anterior no pós-teste.

\begin{tabular}{|c|c|c|c|c|c|c|c|}
\hline Variável & $\left({ }^{\circ}\right)$ & $\begin{array}{c}\text { Média pré (EP) } \\
\left(^{\circ}\right)\end{array}$ & $\begin{array}{c}\text { Média pós (EP) } \\
\left({ }^{\circ}\right)\end{array}$ & Dif. $\left({ }^{\circ}\right)$ & IC 95\% & $P$ valor & TE \\
\hline \multirow{9}{*}{$\begin{array}{c}\text { Inc. } \\
\text { anterior }\end{array}$} & $\operatorname{Rep}^{\circ}$ & $-5,12( \pm 1,2)$ & $-5,27( \pm 1,5)$ & 0,14 & $(-1,59 / 1,87)$ & 0,86 & 0,03 \\
\hline & $30^{\circ}$ & $-3,16( \pm 1,6)$ & $-3,84( \pm 1,7)$ & 0,67 & $(-0.62 / 1,96)$ & 0.28 & 0,10 \\
\hline & $60^{\circ}$ & $-3,44( \pm 2)$ & $-4,07( \pm 2)$ & 0,63 & $(-0,38 / 1,65)$ & 0,20 & 0,08 \\
\hline & $90^{\circ}$ & $-3,84( \pm 2,3)$ & $-4,61( \pm 2,4)$ & 0,77 & $(-0,31 / 1,84)$ & 0,15 & 0,08 \\
\hline & $120^{\circ}$ & $-2,45( \pm 2,1)$ & $-4,77( \pm 2,5)$ & 2,31 & $(0,12 / 3,55)$ & $0,04 *$ & 0,22 \\
\hline & $120^{\circ}$ & $-1,90( \pm 1,9)$ & $-4,59( \pm 2,3)$ & 2,69 & $(0,09 / 4,16)$ & $0,04 *$ & 0,32 \\
\hline & $90^{\circ}$ & $-4,96( \pm 1,8)$ & $-5,37( \pm 2,4)$ & 0,41 & $(-1,45 / 2,28)$ & 0,64 & 0,05 \\
\hline & $60^{\circ}$ & $-5,89( \pm 1,8)$ & $-6,41( \pm 2,3)$ & 0,52 & $(-1,09 / 2,12)$ & 0,50 & 0,22 \\
\hline & $30^{\circ}$ & $-5,67( \pm 1,7)$ & $-6,25( \pm 1,9)$ & 0,58 & $(-1,03 / 2,20)$ & 0,76 & 0,08 \\
\hline
\end{tabular}

Rep: repouso Dif: diferença; EP: erro padrão; IC: intervalo de confiança da diferença. * p < 0,05.

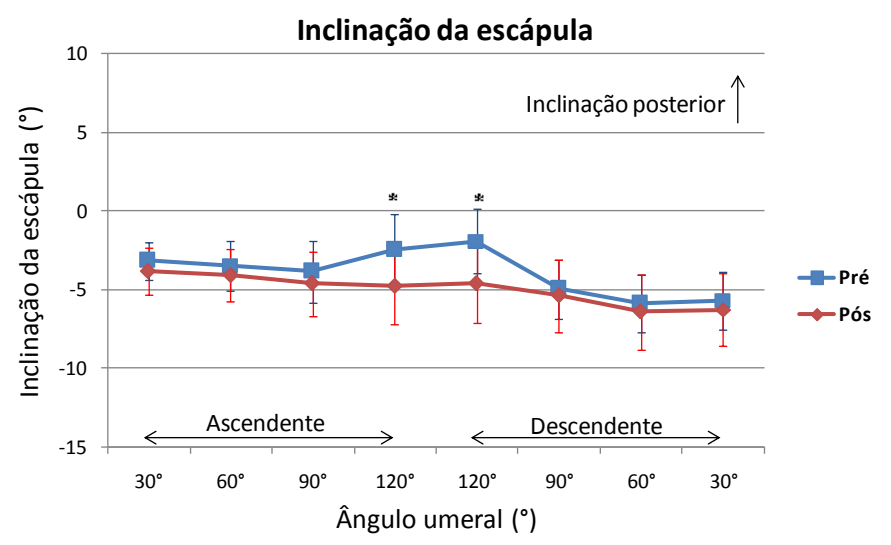

Figura 10: Medidas angulares do movimento da inclinação anterior em relação ao tórax durante o movimento de elevação e abaixamento do braço no plano da escápula. 


\section{2- Eletromiografia}

Os valores de amplitude eletromiográfica dos músculos TD, TA, SA e TT são apresentados na Tabela-5 expressos como porcentagem da CVM (\% CVM) durante os três intervalos de elevação umeral na fase descendente do movimento antes e após a realização do teste de esforço máximo. Os valores estão em forma de MED e EP, diferença entre o pré e pós teste, IC da diferença, valor de $p$ e TE. Foram encontradas diferenças estatisticamente significativas para o músculo SA nos intervalos de $60-30^{\circ}$ e $120-90^{\circ}(\mathrm{p}=0,04 ; \mathrm{p}=0,02)$. O TE foi considerado moderado para ambos $(d=0,57 ; d=0,56)$. A figura 11 ilustra os dados referentes ao RMS dos músculos TD, TA, AS e TT nas janelas de $120^{\circ}-90^{\circ}, 90^{\circ}-60$ e $60^{\circ}-30^{\circ}$ da fase descendente do movimento do braço.

Tabela-5 Atividade eletromiográfica normalizada pela CIVM durante os três intervalos de elevação umeral na fase descendente do movimento do braço.

\begin{tabular}{cccccccc}
\hline \multirow{2}{*}{ Músculo } & $\left({ }^{\circ}\right)$ & Pré & Pós & Dif. $\left({ }^{\circ}\right)$ & IC 95\% & P valor & TE \\
& $60-30^{\circ}$ & $13,89( \pm 1,6)$ & $15,26( \pm 2,4)$ & $-1,37$ & $(-5,36 / 2,61)$ & 0,47 & 0,17 \\
TD & $90-60^{\circ}$ & $12,26( \pm 1,4)$ & $13,55( \pm 1,8)$ & $-1,29$ & $(-3,52 / 0,93)$ & 0,23 & 0,20 \\
& $120-90^{\circ}$ & $13,52( \pm 1,8)$ & $16,04( \pm 2,9)$ & $-2,52$ & $(-8,5 / 3,47)$ & 0,38 & 0,26 \\
& $60-30^{\circ}$ & $23,88( \pm 2,7)$ & $20,01( \pm 1,9)$ & 3,86 & $(-3,43 / 11,19)$ & 0,27 & 0,41 \\
TA & $90-60^{\circ}$ & $17,16( \pm 2,3)$ & $16,03( \pm 2,4)$ & 1,12 & $(-5,17 / 7,42)$ & 0,70 & 0,12 \\
& $120-90^{\circ}$ & $20,10( \pm 2,3)$ & $17,83( \pm 2,1)$ & 2,27 & $(-2,91 / 7,46)$ & 0,36 & 0,26 \\
& $60-30^{\circ}$ & $27,19( \pm 2,2)$ & $22,59( \pm 1,8)$ & 4,59 & $(0,34 / 8,84)$ & $0,04 *$ & 0,57 \\
SA & $90-60^{\circ}$ & $15,84( \pm 1,6)$ & $13,97( \pm 1,5)$ & 1,87 & $(-1,59 / 5,33)$ & 0,26 & 0,30 \\
& $120-90^{\circ}$ & $21,76( \pm 1,8)$ & $17,60( \pm 1,9)$ & 4,16 & $(0,71 / 7,60)$ & $0,02 *$ & 0,56 \\
& $60-30^{\circ}$ & $15,94( \pm 3)$ & $13,29( \pm 2,5)$ & 2,64 & $(-2,36 / 7,65)$ & 0,27 & 0,24 \\
TT & $90-60^{\circ}$ & $13,98( \pm 3)$ & $12,55( \pm 2,1)$ & 1,42 & $(-4,05 / 6,90)$ & 0,58 & 0,14 \\
& $120-90^{\circ}$ & $15,04( \pm 1,8)$ & $13,36( \pm 2,5)$ & 1,68 & $(-4,54 / 7,90)$ & 0,57 & 0,15 \\
\hline
\end{tabular}

Dif: diferença; DP: desvio padrão; IC: intervalo de confiança da diferença. * $\mathrm{p}<0,05$. 

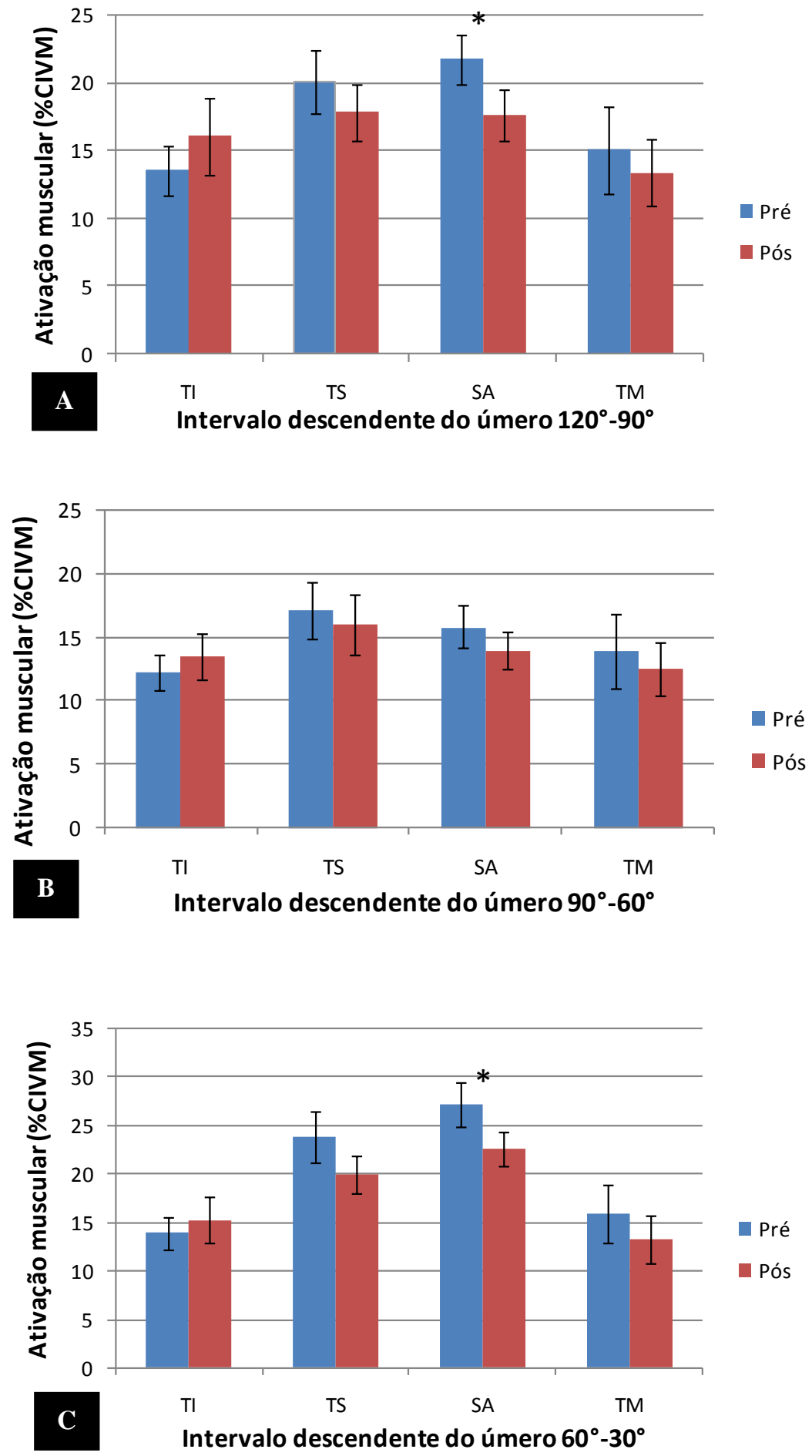

Figura 11: Root means square (RMS) dos músculos trapézio descendente, superior médio e serrátil anterior durante o movimento do braço na fase descendente nas janelas de $120^{\circ}-90^{\circ}(\mathrm{A}), 90^{\circ}-60^{\circ}(\mathrm{B})$ e $60^{\circ}$ $30^{\circ}(\mathrm{C})$. 


\section{3- Poder explicativo da atividade muscular sobre a cinemática}

Os gráficos de dispersão demonstram a relação linear entre a variação do pré e pós teste da cinemática e atividade muscular durante a fase descendente do movimento do braço.

A figura- 6 apresenta os resultados da VC da inclinação anterior a $90^{\circ}$ e $60^{\circ}$ em relação à VAM do TT $120-90^{\circ}$ e $\mathrm{TD} 60-30^{\circ}$ respectivamente. O coeficiente de determinação demonstrou que 38\% (p=0,01) da variação da VC em relação à inclinação da escápula em 90 de elevação pode ser explicada pelo músculo TT no intervalo $120-90^{\circ}$. O músculo TD no intervalo de $60-30^{\circ}$ foi responsável em $42 \%(\mathrm{p}=0,01)$ da variação da inclinação escapular a $60^{\circ}$ de elevação.

A figura-7 apresenta os resultados da VC da rotação interna a $120^{\circ}, 90^{\circ}, 60^{\circ}$ e $30^{\circ} \mathrm{em}$ relação à VAM do TT $120-90^{\circ}$ para os dois primeiros e do SA $60-30^{\circ}$ para os dois últimos. O TT no intervalo de $120-90^{\circ}$ foi responsável em $38 \%$ e $42 \%(\mathrm{p}=0,01 ; \mathrm{p}=0,01)$ em relação à variação da rotação interna da escápula a $120^{\circ}$ e $90^{\circ}$ de elevação do braço respectivamente. $\mathrm{O}$ músculo SA $60-30^{\circ}$ contribuiu em $25 \%$ e $31 \%(\mathrm{p}=0,04 ; \mathrm{p}=0,03)$ da variação da rotação interna a $60^{\circ}$ e $30^{\circ}$ respectivamente.

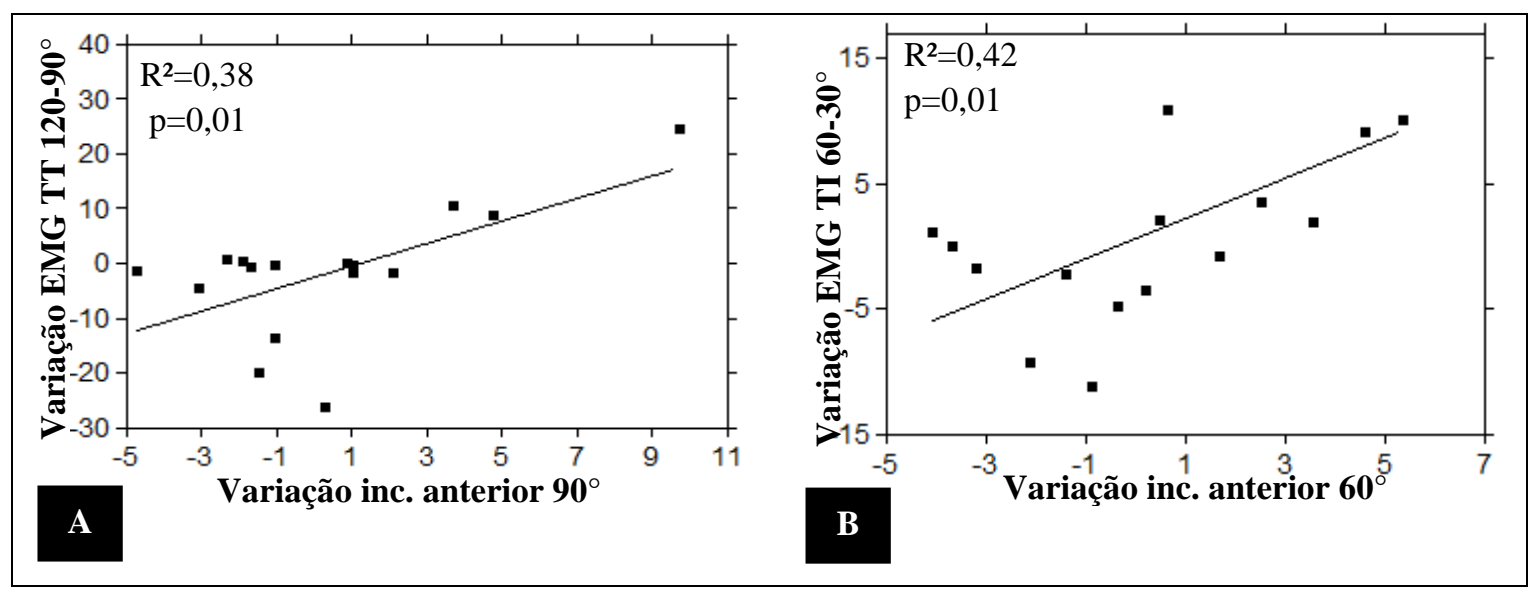

Figura-12: Gráfico de dispersão da VC da inclinação anterior a $90^{\circ}$ e $60^{\circ}$ em relação a VAM do TT 120$90^{\circ}$ e TI 60-30. $\mathrm{R}^{2}=$ coeficiente de determinação, $\mathrm{p}<0,05$. 

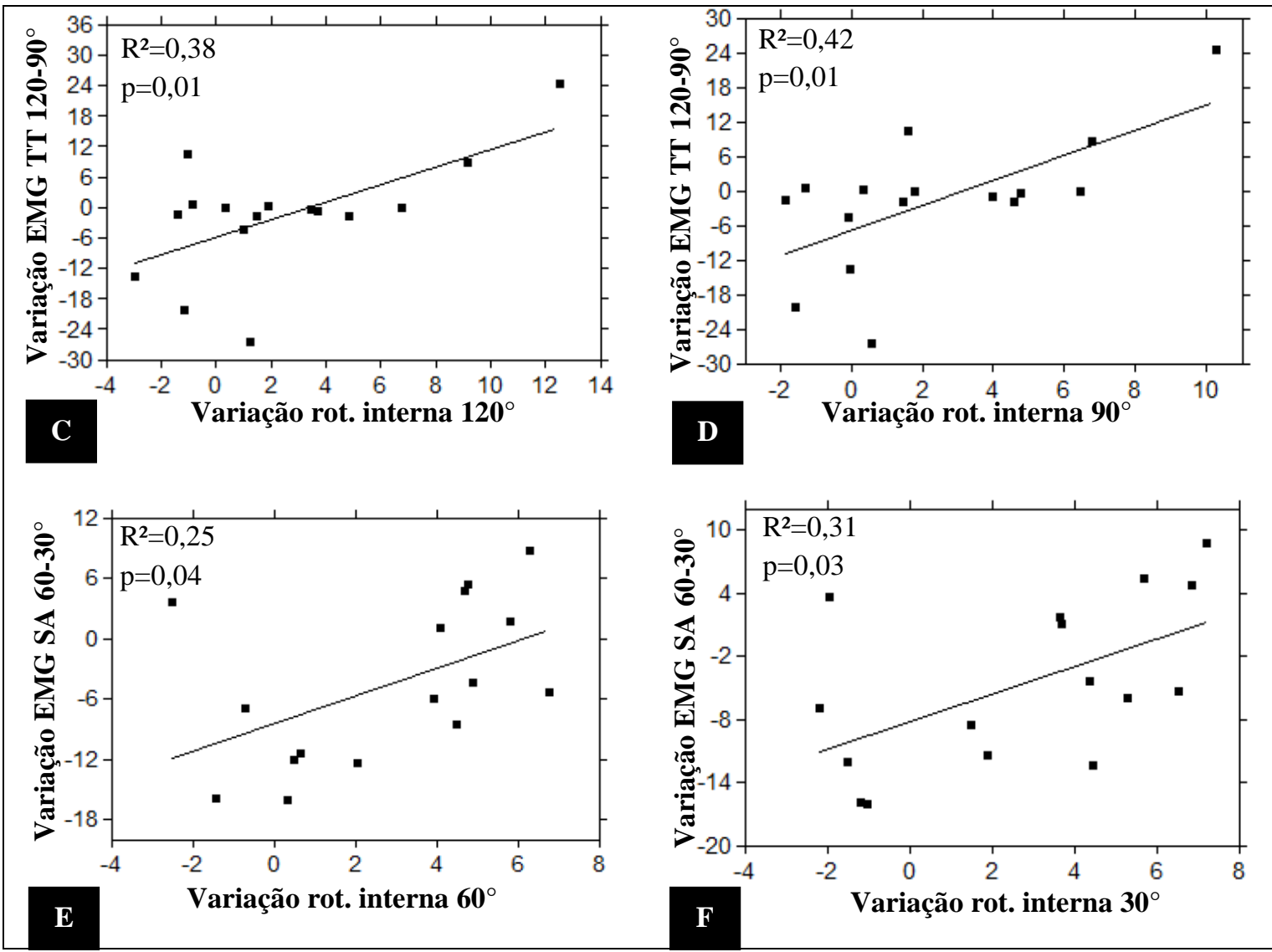

Figura-13: Gráfico de dispersão da $\mathrm{VC}$ da rotação interna a $120^{\circ}, 90^{\circ}, 60^{\circ}$ e $30^{\circ}$ em relação a VAM do TT $120-90^{\circ}$ e TI 60-30. $\mathrm{R}^{2}=$ coeficiente de determinação, $\mathrm{p}<0,05$. 


\section{8- DISCUSSÃO}

O objetivo central deste trabalho foi comparar as rotações da articulação escapulotorácica e a amplitude eletromiográfica de músculos periescapulares após a realização de um teste de esforço máximo em nadadores. Secundariamente foi analisar como as alterações da atividade eletromiográfica influenciaram na cinemática da articulação ET.

Os resultados mostraram aumento da inclinação anterior da escápula a $120^{\circ}$ de elevação do ombro, aumento da rotação interna durante toda a ADM e diminuição da rotação superior apenas em repouso. Resultados semelhantes foram encontrados em sujeitos com dor no ombro (LUDEWING; COOK, 2000; PHADKE; CAMARGO; LUDEWIG, 2009; STRUYF et al., 2014) e assintomáticos que apresentam discinese escapular (HUANG et al., 2015). Estudos futuros com acompanhamento longitudinal destes pacientes são necessários para confirmar ou refutar a relação entre o aumento da inclinação anterior da escápula e o aparecimento de dor no ombro.

A avaliação cinemática da articulação ET é amplamente utilizada em estudos para analisar alterações no ombro e comparação entre situações diversas. No presente trabalho, foi utilizado o método de avaliação com câmera infravermelho proposto por Warner et al. (2013), que apresenta alta confiabilidade entre dias para avaliações da rotação superior e inclinação anterior com coeficiente de correlação múltipla de 0,92 e 0,70 respectivamente. Desta maneira o método utilizado apresenta uma medida confiável para avaliação da rotação superior e inclinação anterior.

Durante movimentos de elevação do ombro as rotações da articulação ET são primordiais para realização da ADM de elevação completa do ombro (TERRY; CHOPP, 2000). A rotação superior da escápula ocorre em maior amplitude elevando a borda lateral do acrômio (FLATOW et al., 1994). A inclinação posterior da escápula eleva a região anterior do acrômio e favorece a passagem do tubérculo maior do úmero sem que ocorra impacto subacromial (FLATOW et al., 1994). No presente trabalho foi encontrado aumento da inclinação anterior da escápula com $120^{\circ}$ de elevação do braço tanto na fase ascendente quanto na descendente do movimento. Tal alteração ocorreu na ADM crítica para ocorrência da SIS (LUDEWIG; REYNOLDS, 2009). Apesar de pequeno $\left(2,69^{\circ}\right)$, o aumento da inclinação anterior foi semelhante aos encontrados em estudos em sujeitos com dor no ombro (COLE LUKASIEWICZ et al., 1999; ENDO, K., IKATA, 2001; LUDEWING; COOK, 2000). A relação de causa e efeito entre as alterações cinemáticas e dor no ombro de nadadores não é clara, porém durante o gesto da braçada na natação o movimento de 
inclinação posterior da escápula é necessário principalmente durante a fase aérea do movimento em que ocorre máxima rotação externa e elevação da articulação do ombro, sobrecarregando a articulação GU (VIRAG et al., 2014).

O impacto do aumento da rotação interna da escápula na cinemática do ombro é incerto. Isso se deve possivelmente a dois fatores: grande variabilidade encontrada entre sujeitos e maior erro dos equipamentos de aferição em relação aos outros movimentos (WARNER; CHAPPELL; STOKES, 2015). Na metodologia usada neste trabalho, o coeficiente de correlação múltipla entre dias foi de 0,53 , considerado moderado/baixo. Com o aumento da rotação interna, teoricamente haveria um incremento relativo da rotação externa da art. GU, o que do ponto de vista anatômico é positivo, pois aumenta o espaço para o tubérculo maior do úmero passar durante os movimentos de elevação. Porém esse aumento relativo pode gerar impacto dos tendões do MR entre o aspecto posterior da cabeça do úmero e a região posterior da glenóide durante movimentos que combinem rotação externa e abdução GU, como vistos na braçada da natação (LUDEWIG; REYNOLDS, 2009; PALEY et al., 2000). Neste trabalho foi observado aumento da rotação interna escapular durante toda a ADM analisada, porém com tamanho de efeito pequeno. Desta maneira as alterações da rotação interna encontradas após o protocolo de fadiga devem ser consideradas com parcimônia, levando-se em consideração o erro inerente da medida e o pequeno tamanho de efeito.

Estudos em cadáveres demonstram que alterações da inclinação anterior da escápula não interferem de maneira significativa na área de contato entre o MR e acrômio durante os movimentos de arremesso (MIHATA et al., 2012) e elevação do braço no plano da escápula (MURAKI et al., 2017). Porém, estes estudos foram realizados em tendões saudáveis. O alto volume de treinamento em nadadores traz consequências para as estruturas anatômicas dos tendões do MR. Cerca de $69 \%$ dos nadadores apresentam tendinopatia de supraespinhal (SEIN et al., 2010). Os tendões lesionados exibem níveis variados de alterações com presença de proliferação celular desorganizada e aumento de espessura, porém com menor qualidade do tecido (HUEGEL; WILLIAMS; SOSLOWSKY, 2015). Em nadadores com tendinopatia no ombro, a relação entre o espaço subacromial e o MR está alterada e mudanças nas rotações escapulares poderiam gerar impacto adicional do MR já lesionado com o acrômio. Desta forma, futuros estudos devem avaliar como as alterações do posicionamento escapular influenciam o espaço subacromial em sujeitos com tendinopatia do MR. 
Modelos experimentais com indução de fadiga foram propostos para analisar alterações biomecânicas na articulação ET. Os padrões de alteração cinemática variam entre estudos e dependem do grupo muscular fadigado.

Protocolos de fadiga dos rotadores externos do ombro foram realizados apresentando resultados diferentes, demonstrando tanto aumento (EBAUGH; MCCLURE; KARDUNA, 2006a; JOSHI et al., 2011) quanto diminuição da rotação superior (TSAI; MCCLURE; KARDUNA, 2003), aumento da rotação interna (TSAI; MCCLURE; KARDUNA, 2003) e aumento da inclinação anterior (EBAUGH; MCCLURE; KARDUNA, 2006a; TSAI; MCCLURE; KARDUNA, 2003). Apesar de apresentar diferenças nos protocolos de fadiga, nosso trabalho encontrou resultados semelhantes em relação ao aumento da inclinação anterior e da rotação interna de escápula. Ebauh et al. (2006a) demonstrou que as alterações na articulação ET são compensatórias as encontradas na articulação GU, visto que houve fadiga dos rotadores externos do MR associada as alterações cinemáticas. Ratificando essa hipótese, Noguchi et al. (2013) realizou um protocolo de fadiga específico para os músculos periescapulares, poupando o MR e esses autores não encontraram nenhuma diferença significativa após a fadiga. No presente estudo foi realizado um protocolo de fadiga que envolveu vários grupos musculares inclusive os do MR. Por isso, não se pode descartar esse mecanismo como causa das alterações cinemáticas encontradas.

Com intuito de simular gestos funcionais, foram realizados protocolos de fadiga com exercícios de elevação dos MMSS e observados aumento da rotação superior (CHOPPHURLEY et al., 2016; CHOPP; FISCHER; DICKERSON, 2011; EBAUGH; MCCLURE; KARDUNA, 2006b), inclinação posterior (CHOPP; FISCHER; DICKERSON, 2011) e rotação interna da escápula (TAKASAKI; LIM; SOON, 2016). Teoricamente o aumento da rotação superior e da inclinação posterior são alterações benéficas, pois fornecem um mecanismo de alívio para as estruturas sob o espaço subacromial. No presente trabalho foram encontrados resultados diferentes quanto à inclinação posterior da escápula. Apesar dos protocolos de fadiga realizados serem globais para musculatura do ombro, apenas em nosso estudo foi evidenciada a queda na ativação do músculo SA. Dentre suas funções, o SA realiza a inclinação posterior e a rotação externa da escápula e uma queda em sua ativação poderia justificar o aumento da inclinação anterior e da rotação interna da escápula.

Pink e colaboradores (1991a) evidenciaram em seu estudo a importância do músculo SA durante o gesto da braçada na natação. O SA permanece ativo durante todo o movimento mantendo níveis eletromiográficos médios de ativação em relação a seu pico, desta forma demonstrando seu papel na estabilização da escápula na parede torácica durante toda a ADM 
do ombro. Interessante ressaltar que em outro estudo de Pink e colaboradores (1991b) em nadadores com dor o ombro o principal achados eletromiográficos foi à diminuição da atividade muscular do SA durante todo o ciclo das braçadas.

Dos músculos analisados neste trabalho, o SA foi o único a apresentar decréscimo de atividade eletromiográfica após o teste de esforço máximo. Durante o teste, o movimento de flexão do ombro foi realizado a favor da resistência elástica, com isso a força necessária para os músculos rodarem a escápula superiormente foi minimizada. Já na fase de extensão do ombro, que ocorreu contra a resistência elástica, os músculos estudados, por se tratarem primordialmente de rotadores superiores da escápula, não precisaram realizar torque primário, apenas alguma ativação sinergista. Porém, sabe-se que o SA além de rodar superiormente a escápula, funciona como principal estabilizador da escápula na parede torácica. Desta maneira o SA foi exigido nas duas fases do movimento, rodando a escápula superiormente durante a flexão do braço e estabilizando a borda medial da escápula durante a extensão. Desta forma, entre os músculos analisados o SA possivelmente foi o que passou maior tempo ativado durante o teste, consequentemente mais exposto a fadiga.

Em relação ao poder explicativo da VAM na cinemática, foi encontrado que voluntários com aumento da inclinação anterior foram os que obtiveram maior aumento da atividade muscular do TD. No mesmo sentido o aumento da rotação interna da escápula foi acompanhado de aumento da atividade muscular do TT nas angulações $120-90^{\circ}$ e do SA em angulações de $60-30^{\circ}$. Conforme a produção de força de um músculo aumenta, a taxa de disparo nas unidades motores cresce. Porém, caso o aumento seja ainda maior a contribuição de força da unidade motora é saturada, e assim cada unidade motora continua a prover energia para o sinal do EMG enquanto a contribuição para força permanece num valor constante. Essa relação não linear causa um aumento maior do sinal do EMG e consequentemente aumento do RMS do que da força produzida (LAWRENCE; DE LUCA, 1983). A relação de $42 \%$ entre o aumento da inclinação anterior e aumento da ativação do TD demonstra que em atletas com as maiores alterações, possivelmente houve uma tentativa por parte do sistema nervoso central de aumentar a atividade muscular do TD como uma estratégia compensatória para suprir a redução na atividade do SA e controlar o aumento da inclinação anterior. Porém o aumento VAM do TD não foi capaz de compensar a queda do SA. Interessante ressaltar que apesar de não apresentar diferença estatística, o TD obteve valores mais altos em todas as angulações no pós teste.

Atletas de natação apresentam adaptações físicas e posturais relacionadas ao esporte. O desequilíbrio entre a musculatura rotadora interna do ombro como peitoral maior e grande 
dorsal, e os músculos posteriores que estabilização a articulação ET, levam a alterações posturais prejudiciais a biomecânica do ombro (HIBBERD et al., 2016a). Essas alterações incluem anteriorização da cabeça e ombro (HIBBERD et al., 2016b), discinese escapular (MADSEN et al., 2011), encurtamento de cápsula posterior (RIEMANN; WITT; DAVIES, 2011) e de peitoral menor (MORAIS; CRUZ, 2016).

Os encurtamentos do músculo peitoral menor e da cápsula posterior do ombro geram aumento da rotação interna e inclinação anterior da escápula (BORICH et al., 2006; MORAIS; CRUZ, 2016). Os efeitos da fadiga somados ao encurtamento dessas estruturas não são conhecidos, mas teoricamente poderiam potencializar as alterações biomecânicas nesses atletas. Não estavam no escopo deste estudo avaliar o encurtamento da cápsula posterior e do peitoral menor e suas repercussões biomecânicas no ombro. Contudo, futuras pesquisas devem levá-las em consideração e analisar como atletas com encurtamento dessas estruturas se comportam em situações de fadiga.

\section{1-Limitações e considerações do estudo}

O presente estudo, em nosso conhecimento, foi o primeiro a investigar a biomecânica tridimensional da escápula em nadadores jovens e a relacionar os achados da cinemática com os eletromiográficos nesta população.

As análises neste estudo foram realizadas logo após o protocolo de fadiga e refletem uma resposta aguda. Os efeitos tardios da fadiga na cinemática tridimensional e atividade muscular da escápula não foram estudados. Porém Hibber et al. (2016b) verificaram que durante a temporada houve diminuição do espaço subacromial e aumento da anteriorização de ombros em atletas de natação saudáveis devido ao acumulo de treinamento. Com isso a realização de estudos que avaliem os efeitos tardios da fadiga na biomecânica do ombro devem ser realizados, no intuito de melhorar a periodização da prevenção e nos programas de reabilitação destes atletas.

O número de voluntários recrutados (16) foi reduzido. Entretanto, optamos por recrutar um grupo homogêneo, apenas atletas do sexo masculino e com um nível de treinamento de moderado a alto (Horas/semana 11,6 $\pm 3,8$ ), o que reduziu nossa população para o estudo. Desta maneira procuramos proporcionar maior qualidade dos dados obtidos através da qualidade da amostra.

Um ponto positivo foi à realização de um teste de fadiga que procurou ser o mais similar possível com a encarada pelos atletas durante o treinamento de natação. A ideia inicial do trabalho era avaliar a cinemática e atividade eletromiográfica do ombro durante o teste. 
Porém os marcadores colocados no PX e IJ ficariam fora do campo de visão das câmeras impossibilitando a construção do modelo biomecânico. Outro fator foi que após a realização de estudos pilotos, foi verificado ruído no sinal EMG durante o teste devido à movimentação intensa dos MMSS. Com isso, foi optado por realizar as avaliações antes e após o teste durante o movimento de elevação no plano escapular amplamente utilizado na literatura.

Durante o teste, a carga nos MMSS foi exercida por uma resistência elástica e a intensidade variou de acordo com a fase do movimento. Contudo, durante a braçada na natação a fase com maior sobrecarga muscular é a subaquática na qual é realizada a extensão do ombro, de maneira semelhante ao do nosso teste.

A análise cinemática utilizou números discretos em angulações especificas para análise de dados. Tal análise tem como grande vantagem a ampla literatura publicada até o presente momento, o que facilita a comparação e discussão dos resultados. Porém, esse tipo de análise pode ser pouco sensível e não leva em consideração a dinâmica tridimensional da escápula e os múltiplos fatores que podem influenciá-la. Possivelmente uma análise considerando todos os pontos da curva de movimento encontrasse resultados diferentes.

A escolha do cálculo da RMS para o EMG se deu pelo seguinte motivo. Para analisar janelas especificas da angulação de elevação do braço foram cortados dados a partir da cinemática. Apesar de controlar o tempo de movimento de elevação e abaixamento do braço, houve pequenas variações entre os voluntários. Desta maneira as janelas cortadas do EMG ficaram com tamanhos ligeiramente diferentes e o cálculo de uma série temporal com envelope linear e integral não pode ser comparado entre sujeito levando em consideração a diferença no tempo. Deste modo, o cálculo do RMS foi à solução mais viável, pois foi calculado através da média dos valores encontrado em cada janela, não levando em consideração o seu tamanho. Por fim o cálculo da regressão entre angulações específicas da cinemática e janelas de angulações do EMG devem ser interpretadas com atenção, pois a comparação é realizada entre um ângulo especifico e a ativação muscular de uma faixa de movimento.

\section{9- Conclusão e implicação clínica}

Em atletas de natação submetidos a um teste de esforço máximo de 3 minutos houve aumento da inclinação anterior da escápula na angulação de $120^{\circ}$ de elevação do braço, além de aumento da rotação interna durante toda a ADM. A atividade muscular do SA decaiu após o teste de esforço máximo. Por se tratar de um músculo atuante durante todo o gesto 
esportivo, estratégias preventivas e de tratamento devem focar no ganho de força e resistência desse músculo com intuito de promover adequada movimentação da articulação ET.

Por fim, embora os resultados obtivessem significância estatística, as diferenças encontradas foram pequenas e as repercussões clínicas dessas alterações são incertas. São necessários estudos longitudinais para verificar as implicações clínicas desses achados. 


\section{Referencias}

BORICH, M. R. et al. Scapular Angular Positioning at End Range Internal Rotation in Cases of Glenohumeral Internal Rotation Deficit relationship identifies a possible mechanism for development of excessive scapular anterior tilt. J Orthop Sports Phys Ther, v. 36, n. 12, p. 926-934, 2006.

BORSTAD, J. D.; LUDEWIG, P. M. The effect of long versus short pectoralis minor resting length on scapular kinematics in healthy individuals. The Journal of orthopaedic and sports physical therapy, v. 35, n. 4, p. 227-38, 2005.

CHANG, H. et al. Recovery of Joint Position Sense in the Shoulder After Muscle Fatigue. J Sport Rehabil., v. 15, p. 312-325, 2006.

CHOPP-HURLEY, J. N. et al. Fatigue-induced glenohumeral and scapulothoracic kinematic variability: Implications for subacromial space reduction. Journal of Electromyography and Kinesiology, v. 29, p. 55-63, 2016.

CHOPP, J. N.; FISCHER, S. L.; DICKERSON, C. R. The specificity of fatiguing protocols affects scapular orientation: Implications for subacromial impingement. Clinical Biomechanics, v. 26, n. 1, p. 40-45, 2011.

CHU, Y. et al. Validation of a video-based motion analysis technique in 3-D dynamic scapular kinematic measurements. Journal of Biomechanics, v. 45, n. 14, p. 2462-2466, 2012.

COHEN, J. Statistical Power Analysis. Current Directions in Psychological Science (Wiley-Blackwell), v. 1, p. 98-101, 1992.

COLE LUKASIEWICZ, A. et al. Comparison of 3-Dimensional Scapular position and Orientation Between -subjects With and Without Shoulder Impingement. Journal of Orthopaedic \& Sports Physical Therapy, v. 29, n. 10, p. 574-586, 1999.

DASHOTTAR, A.; BORSTAD, J. Posterior glenohumeral joint capsule contracture. Shoulder \& Elbow, v. 4, n. 4, 2012.

EBAUGH, D. D.; MCCLURE, P. W.; KARDUNA, A. R. Scapulothoracic and glenohumeral kinematics following an external rotation fatigue protocol. The Journal of orthopaedic and sports physical therapy, v. 36, n. 8, p. 557-571, 2006a.

EBAUGH, D. D.; MCCLURE, P. W.; KARDUNA, A. R. Effects of shoulder muscle fatigue caused by repetitive overhead activities on scapulothoracic and glenohumeral kinematics. Journal of Electromyography and Kinesiology, v. 16, n. 3, p. 224-235, 2006b.

EKSTROM, R. A. et al. Comparing the function of the upper and lower parts of the serratus anterior muscle using surface electromyography. J Orthop Sports Phys Ther, v. 34, n. 5, p. 235-243, 2004. 
EKSTROM, R. A.; SODERBERG, G. L.; DONATELLI, R. A. Normalization procedures using maximum voluntary isometric contractions for the serratus anterior and trapezius muscles during surface EMG analysis. Journal of Electromyography and Kinesiology, v. 15, n. 4, p. 418-428, 2005.

ENDO, K., IKATA, T. . Radiographic assessment of scapular rotational title in chronic shoulder impingement syndrome. Journal of Orthopaedic Science, v. 32, p. 248-259, 2001. FLATOW, E. L. et al. Excursion of the rotator cuff under the acromion. Patterns of subacromial contact. The American journal of sports medicine, v. 22, n. 6, p. 779-788, 1994.

HEINLEIN, S. A.; COSGAREA, A. J. Biomechanical Considerations in the Competitive Swimmer's Shoulder. Sports health, v. 2, n. 6, p. 519-25, 2010.

HERMENS, H. J. et al. European Recommendations for Surface ElectroMyoGraphy. Roessingh Research and Development, p. 8-11, 1999.

HEWITT, P. G. Fundamentos de física conceitual. Bookman Brasil, 2009.

HIBBERD, E. E. et al. Comparison of upper extremity physical characteristics between adolescent competitive swimmers and nonoverhead athletes. Journal of Athletic Training, v. 51, n. 1, p. 65-69, 2016a.

HIBBERD, E. E. et al. Effect of Swim Training on the Physical Characteristics of Competitive Adolescent Swimmers. The American journal of sports medicine, v. 44, n. 11, p. 2813-2819, 2016b.

HOARD, R. W. et al. MEASURING SCAPULAR MOVEMENT USING THREEDIMENSIONAL ACROMIAL PROJECTION Ronald. Shoulder \& Elbow, v. 5, n. 2, p. 93 99, 2013.

HUANG, T. S. et al. Specific kinematics and associated muscle activation in individuals with scapular dyskinesis. Journal of Shoulder and Elbow Surgery, v. 24, n. 8, p. 1227-1234, 2015.

HUEGEL, J.; WILLIAMS, A. A.; SOSLOWSKY, L. J. Rotator cuff biology and biomechanics: a review of normal and pathological conditions. Current rheumatology reports, v. 17, n. 1, p. 476, 2015.

JOSHI, M. et al. Shoulder external rotation fatigue and scapular muscle activation and kinematics in overhead athletes. Journal of Athletic Training, v. 46, n. 4, p. 349-357, 2011.

KARDUNA, A. R. et al. Dynamic measurements of three-dimensional kinematics: A validation study. Journal of biomechanical engineering, v. 123, n. April, p. 184-190, 2001.

KIBLER, W. BEN et al. Clinical implications of scapular dyskinesis in shoulder injury: the 2013 consensus statement from the "Scapular Summit". British journal of sports medicine, v. 47, n. 14, p. 877-885, 2013. 
KIBLER, W. BEN; SCIASCIA, A. Current concepts : scapular dyskinesis Current concepts : scapular dyskinesis. Sports Medicine, n. 1, p. 300-305, 2010.

LAWRENCE, J. H.; DE LUCA, C. J. Myoelectric signal versus force relationship in different human muscles. Journal of applied physiology (Bethesda, Md. : 1985), v. 54, n. 6, p. 1653$1659,1983$.

LEITE, M. L., FALOPPA, F. Propedêutica ortopédica e traumatológica [s.l.] Artmed Brasil, 2013.

LEMPEREUR, M. et al. Validity and reliability of 3D marker based scapular motion analysis: A systematic review. Journal of Biomechanics, v. 47, n. 10, p. 2219-2230, 2014.

LUDEWIG, P. M. et al. Motion of the shoulder complex during multiplanar humeral elevation. The Journal of bone and joint surgery. American volume, v. 91, n. 2, p. 378-89, 2009.

LUDEWIG, P. M.; COOK, T. M.; NAWOCZENSKI, D. A. Three-dimensional scapular orientation and muscle activity at selected positions of humeral elevation. The Journal of orthopaedic and sports physical therapy, v. 24, n. 2, p. 57-65, 1996.

LUDEWIG, P. M.; REYNOLDS, J. F. The Association of scapulair Kinematics and Glenohumeral Joint Pathologies. Journal orthopedics Sports Physical Therapy, v. 39, n. 2, p. $90-104,2009$.

LUDEWING, P. M.; COOK, T. M. Alterations in Shoulder Kinematics and Associated Muscle Activity in People With. Physical Therapy, v. 80, n. 3, p. 276-291, 2000.

MACINTOSH, B. R.; RASSIER, D. E. What is fatigue? Can J Appl Physiol, v. 27, n. 1, p. 42-55, 2002.

MADSEN, P. H. et al. Training induces scapular dyskinesis in pain-free competitive swimmers: a reliability and observational study. Clinical journal of sport medicine : official journal of the Canadian Academy of Sport Medicine, v. 21, n. 2, p. 109-113, 2011.

MCCLURE, P. W. et al. Direct 3-dimensional measurement of scapular kinematics during dynamic movements in vivo. Journal of Shoulder and Elbow Surgery, v. 10, n. 3, p. 269$277,2001$.

MCLEAN, L. et al. The effect of head position, electrode site, movement and smoothing window in the determination of a reliable maximum voluntary activation of the upper trapezius muscle. Journal of Electromyography and Kinesiology, v. 13, n. 2, p. 169-180, 2003.

MCQUADE, K.; SMIDT, G. L. Scapulothoracic Muscle Fatigue Associated with Alterations in Scapulohumeral Rhythm Kinematics During Maximum Resistive Shoulder Elevation. J Orthop Sports Phys Ther, v. 28, n. 2, p. 74-80, 1998.

MEYER, K. E. et al. Three-dimensional scapular kinematics during the throwing motion. Journal of Applied Biomechanics, v. 24, n. 1, p. 24-34, 2008. 
MIHATA, T. et al. Effect of scapular orientation on shoulder internal impingement in a cadaveric model of the cocking phase of throwing. The Journal of bone and joint surgery. American volume, v. 94, n. 17, p. 1576-83, 2012.

MORAIS, N.; CRUZ, J. The pectoralis minor muscle and shoulder movement-related impairments and pain: Rationale, assessment and management. Physical Therapy in Sport, v. 17, p. 1-13, 2016.

MURAKI, T. et al. The effect of scapular position on subacromial contact behavior: a cadaver study. Journal of Shoulder and Elbow Surgery, 2017.

PALEY, K. J. et al. Arthroscopic findings in the overhand throwing athlete: evidence for posterior internal impingement of the rotator cuff. Arthroscopy: the journal of arthroscopic \& related surgery : official publication of the Arthroscopy Association of North America and the International Arthroscopy Association, v. 16, n. 1, p. 35-40, 2000 .

PHADKE, V. et al. Comparison of Glenohumeral Motion Using Different Rotation Sequences. Journal of Biomechanics, v. 44, n. 4, p. 700-705, 2011.

PHADKE, V.; CAMARGO, P. R.; LUDEWIG, P. M. Scapular and rotator cuff muscle activity during arm elevation: A review of normal function and alterations with shoulder impingement. Revista Brasileira de Fisioterapia, v. 13, n. 1, p. 1-9, 2009.

PINK, M. et al. The normal shoulder during freestyle swimming. An electromyographic and cinematographic analysis of twelve muscles. Am J Sports Med, v. 19, n. 6, p. 569-576, 1991.

PINK, M. et al. The painful shoulder during freestyle swimming. An electromyographic and cinematographic analysis of twelve muscles. Am J Sports Med, v. 19, n. 6, p. 577-582, 1991.

PINK, M.; TIBONE, J. The Painful Shoulder in the Swimming Athlete. Orthop Clin North Am, v. 31, n. 2, p. 246-261, 2000.

RADWAN, A. et al. Is there a relation between shoulder dysfunction and core instability? International journal of sports physical therapy, v. 9, n. 1, p. 8-13, 2014.

REED, D. et al. Does load influence shoulder muscle recruitment patterns during scapular plane abduction? Journal of Science and Medicine in Sport, v. 19, n. 9, p. 755-760, 2016.

RIEMANN, B. L.; WITT, J.; DAVIES, G. J. Glenohumeral joint rotation range of motion in competitive swimmers. J Sports Sci, v. 29, n. 11, p. 1191-1199, 2011.

ROGOWSKI, I. et al. Scapulothoracic kinematics during tennis forehand drive. Sports biomechanics / International Society of Biomechanics in Sports, v. 13, n. 2, p. 166-75, 2014.

ROY, J. S. et al. The reliability of three-dimensional scapular attitudes in healthy people and people with shoulder impingement syndrome. BMC Musculoskelet Disord, v. 8, p. 49, 2007. 
RUNDQUIST, P. J.; OBRECHT, C.; WOODRUFF, L. Three-dimensional shoulder kinematics to complete activities of daily living. American journal of physical medicine $\boldsymbol{\&}$ rehabilitation / Association of Academic Physiatrists, v. 88, n. 8, p. 623-629, 2009.

SCHÜLDT, K., HARMS-RINGDAHL, K. Activity levels during isometric test contractions of neck and shoulder muscles. Scandinavian Journal of Rehabilitation Medicine, v. 20, n.3, p.117-127, 1988.

SEIN, M. L. et al. Shoulder pain in elite swimmers: primarily due to swim-volume-induced supraspinatus tendinopathy. Br J Sports Med, v. 44, p. 105-113, 2010.

SHEIKHZADEH, A. et al. Three-dimensional motion of the scapula and shoulder during activities of daily living. Journal of Shoulder and Elbow Surgery, v. 17, n. 6, p. 936-942, 2008.

SOUSA, C. DE O. et al. Motion of the shoulder complex in individuals with isolated acromioclavicular osteoarthritis and associated with rotator cuff dysfunction: Part 2 - Muscle activity. Journal of Electromyography and Kinesiology, v. 25, n. 1, p. 77-83, 2015.

STIRN, I. et al. Evaluation of muscle fatigue during 100-m front crawl. European Journal of Applied Physiology, v. 111, n. 1, p. 101-113, 2011.

STRUYF, F. et al. Scapulothoracic muscle activity and recruitment timing in patients with shoulder impingement symptoms and glenohumeral instability. Journal of Electromyography and Kinesiology, v. 24, n. 2, p. 277-284, 2014.

TAKASAKI, H.; LIM, E. C. W.; SOON, B. The effect of shoulder muscle fatigue on active repositioning acuity and scapulothoracic resting alignment: A systematic review with metaanalysis. Physical Therapy in Sport, v. 20, p. 61-78, 2016.

TEECE, R. M. et al. Three-dimensional acromioclavicular joint motions during elevation of the arm. The Journal of orthopaedic and sports physical therapy, v. 38, n. 4, p. 181-90, 2008.

TERRY, G. C.; CHOPP, T. M. Functional Anatomy of the Shoulder. Journal of Athletic Training, v. 35, n. 3, p. 248-255, 2000.

TOVIN, B. J. Prevention and Treatment of Swimmer's Shoulder. North American journal of sports physical therapy : NAJSPT, v. 1, n. 4, p. 166-75, 2006.

TSAI, N. T.; MCCLURE, P. W.; KARDUNA, A. R. Effects of muscle fatigue on 3dimensional scapular kinematics. Archives of Physical Medicine and Rehabilitation, v. 84, n. 7, p. 1000-1005, 2003.

TUCKER, W. S. et al. Scapular Muscle Activity in Overhead Athletes With Symptoms of Secondary Shoulder Impingement During Closed Chain Exercises. Archives of Physical Medicine and Rehabilitation, v. 91, n. 4, p. 550-556, 2010. 
VEEGER, H. E. The position of the rotation center of the glenohumeral joint. Jounal of Biomechanics, v. 33, n. 12, p. 1711-1715, Dec. 2000.

VIRAG, B. et al. Prevalence of Freestyle Biomechanical Errors in Elite Competitive Swimmers. Sports Health: A Multidisciplinary Approach, v. 6, n. 3, p. 218-224, 2014.

WADSWORTH, D. J.; BULLOCK-SAXTON, J. E. Recruitment patterns of the scapular rotator muscles in freestyle swimmers with subacromial impingement. International journal of sports medicine, v. 18, n. 8, p. 618-24, 1997.

WARNER, M. B. et al. Objective classification of scapular kinematics in participants with movement faults of the scapula on clinical assessment. Computer methods in biomechanics and biomedical engineering, v. 5842, n. September 2014, p. 37-41, 2013.

WARNER, M. B.; CHAPPELL, P. H.; STOKES, M. J. Measuring scapular kinematics during arm lowering using the acromion marker cluster. Human Movement Science, v. 31, n. 2, p. 386-396, 2012.

WARNER, M. B.; CHAPPELL, P. H.; STOKES, M. J. Measurement of Dynamic Scapular Kinematics Using an Acromion Marker Cluster to Minimize Skin Movement Artifact. Journal of Visualized Experiments, n. 96, p. 1-14, 2015.

WESTON, M. et al. Isolated Core Training Improves Sprint Performance in National- Level Junior... p. 204-210, 2015.

WOLF, B. R. et al. Injury patterns in Division I collegiate swimming. The American journal of sports medicine, v. 37, n. 10, p. 2037-42, 2009.

WU, G. et al. ISB recommendation on definitions of joint coordinate systems of various joints for the reporting of human joint motion - Part II: Shoulder, elbow, wrist and hand. Journal of Biomechanics, v. 38, n. 5, p. 981-992, 2005. 


\section{Anexo 1}

\section{Escola de Educação Física e Esporte de Ribeirão Preto Programa de Pós Graduação em Reabilitação e Desempenho Funcional}

\section{TERMO DE ASSENTIMENTO LIVRE E ESCLARECIDO DOS VOLUNTÁRIOS}

\section{Pesquisador responsável: Felipe de Souza Serenza.}

\section{Orientador: Prof. Dr. Paulo Roberto Pereira Santiago}

Você está sendo convidado a participar como voluntário da pesquisa: "Análise neuromecânica da cintura escapular em nadadores após a realização do teste All Out 3 min”. Lesões nos ombros apresentam alta incidência em vários esportes sendo que entre nadadores correspondem por $40 \%$ de todas as lesões. Os mecanismos relacionados a tais problemas ainda não são totalmente conhecidos, porém varias patologias são ligadas a alta carga de treinamento e a um pobre controle neuromuscular do complexo do ombro. Com isso, o objetivo deste estudo é analisar a movimentação (por vídeo) e a atividade muscular durante um teste que leve voluntário a uma situação semelhante à de seu treinamento.

\section{Procedimentos}

Em caso de participação deste estudo é importante que você saiba dos seguintes procedimentos que serão realizados. Todas as análises realizadas em apenas um encontro dentro do Laboratório de Biomecânica e Controle Motor (LaBioCom) na Escola de Educação Física e Esporte de Ribeirão Preto. Inicialmente será aplicado um questionário contendo dados pessoais (nome, idade, peso), treinamento (anos de prática, horas de treino por semana) e lesões prévias. Em seguida uma avaliação física do ombro será realizada, contendo testes específicos. Estes testes são para avaliar a amplitude de rotação dos ombros, o encurtamento do músculo peitoral menor (anteriorização do ombro) e o movimento de elevação do seu ombro. Por fim será realizada a análise de movimento por vídeo e atividade elétrica dos músculos. Para isso, serão colocados marcadores adesivos nos ombros e tronco, bem como sensores de atividade muscular na região posterior do ombro. Após a colocação do aparato, será realizado o teste máximo de esforço chamado All Out 3 minutos. O voluntário realizará o gesto esportivo do nado sobre um banco de natação. Suas mãos estarão acopladas a um palmar e este a uma resistência elástica presa a um suporte na parede. Então será realizado o 
teste de máximo esforço durante 3 minutos. A análise de vídeo e da atividade muscular será realizada durante o teste.

\section{Possíveis benefícios}

Trata-se de uma avaliação realizada em apenas uma coleta sem acompanhamento posterior dos participantes, por isso não existem benefícios diretos individuais. Existem benefícios gerais para o entendimento da movimentação e atividade dos músculos do ombro em condições de cansaço. Com isso informações acerca do desempenho e mecanismos de lesão do ombro podem ser elucidados. Além disso, você está informada de que apenas as despesas de transporte e um lanche simples, com água, bolacha e uma fruta serão custeados pelos pesquisadores. Não haverá ressarcimento do ponto de vista financeiro por parte dos pesquisadores ou da Instituição.

\section{Desconforto e risco}

Todas as tarefas realizadas no presente estudo apresentam o mínimo de desconforto, sendo que o voluntário pode ter dor muscular ou dor no ombro após o teste. Assim, um examinador estará constantemente ao seu lado se eventualmente alguma ajuda for necessária durante execução dos testes. Você não será submetida a nenhum procedimento sem o seu conhecimento e consentimento, bem como receberá indenização diante de eventuais danos decorrentes da pesquisa conforme leis vigentes no país. 


\section{Liberdade de participação e sigilo de identidade}

A participação no estudo é totalmente voluntária, e você pode interrompê-la a qualquer momento sem nenhum prejuízo à sua pessoa, e por obrigação, os pesquisadores responsáveis excluirão todos os seus dados. Todos os dados pessoais e informações obtidas neste estudo serão confidenciais, e seu nome não será divulgado em momento algum. Entretanto, os dados obtidos poderão ser utilizados para fins didáticos e científicos, desde que seu anonimato seja resguardado.

Para qualquer dúvida durante todas as fases da pesquisa, favor contatar:

-Felipe de Souza Serenza.

Mestrando do Programa de Pós Graduação em Reabilitação e Desempenho Funcional da Faculdade de Medicina de Ribeirão Preto (FMRP/USP).

Fone: (16) 984835973 ou pelo e-mail: fsserenza@gmail.com

Para esclarecimentos éticos da pesquisa:

Comitê de Ética em Pesquisa do Comitê de Ética da EEFERP/USP: (16) 3315-0494, cep90@usp.br

$\mathrm{Eu}$,

RG data de nascimento na cidade residente estado

telefone (_ concordo em participar da pesquisa em que os responsáveis me explicaram todos os riscos envolvidos, o objetivo da pesquisa, se prontificaram a responder todas as minhas dúvidas sobre os procedimentos, além de entregar uma via deste Termo de Consentimento Livre e Esclarecido.

Ribeirão Preto, de de 
Anexo 2

\section{Escola de Educação Física e Esporte de Ribeirão Preto Programa de Pós Graduação em Reabilitação e Desempenho Funcional}

\section{TERMO DE CONSENTIMENTO LIVRE E ESCLARECIDO DOS REPRESENTANTES LEGAIS}

\section{Pesquisador responsável: Felipe de Souza Serenza. \\ Orientador: Prof. Dr. Paulo Roberto Pereira Santiago}

Pedimos sua permissão para que seu filho possa participar de um estudo sendo voluntário da pesquisa: "Análise neuromecânica da cintura escapular em nadadores após a realização do teste All Out 3 min". Lesões nos ombros apresentam alta incidência em vários esportes sendo que entre nadadores correspondem por $40 \%$ de todas as lesões. Os mecanismos relacionados a tais problemas ainda não são totalmente conhecidos, porém varias patologias são ligadas a alta carga de treinamento e a um pobre controle neuromuscular do complexo do ombro. Com isso, o objetivo deste estudo é analisar a movimentação (por vídeo) e a atividade muscular durante um teste que leve voluntário a uma situação semelhante à de seu treinamento.

\section{Procedimentos}

Em caso de participação deste estudo é importante que você e seu filho saibam dos seguintes procedimentos que serão realizados. Todas as análises serão realizadas em apenas um encontro dentro do Laboratório de Biomecânica e Controle Motor (LaBioCom) na Escola de Educação Física e Esporte de Ribeirão Preto. Inicialmente será aplicado um questionário contendo dados pessoais (nome, idade, peso), treinamento (anos de prática, horas de treino por semana) e lesões prévias. Em seguida uma avaliação física do ombro será realizada, contendo testes específicos. Estes testes são para avaliar a amplitude de rotação dos ombros, o encurtamento do músculo peitoral menor (anteriorização do ombro) e o movimento de elevação do seu ombro. Por fim será realizada a análise de movimento por vídeo e atividade elétrica dos músculos. Para isso, serão colocados marcadores adesivos nos ombros e tronco, bem como sensores de atividade muscular na região posterior do ombro. Após a colocação do aparato, será realizado o teste máximo de esforço chamado All Out 3 minutos. O voluntário realizará o gesto esportivo do nado sobre um banco de natação. Suas mãos estarão acopladas a um palmar e este a uma resistência elástica presa a um suporte na parede. Então será realizado 
o teste de máximo esforço durante 3 minutos. A análise de vídeo e da atividade muscular será realizada durante o teste.

\section{Possíveis benefícios}

Trata-se de uma avaliação realizada em apenas uma coleta sem acompanhamento posterior dos participantes, por isso não existem benefícios diretos individuais. Existem benefícios gerais para o entendimento da movimentação e atividade dos músculos do ombro em condições de cansaço. Com isso informações acerca do desempenho e mecanismos de lesão do ombro podem ser elucidados. Além disso, você está informada de que apenas as despesas de transporte e um lanche simples, com água, bolacha e uma fruta serão custeados pelos pesquisadores. Não haverá ressarcimento do ponto de vista financeiro por parte dos pesquisadores ou da Instituição.

\section{Desconforto e risco}

Todas as tarefas realizadas no presente estudo apresentam o mínimo de desconforto, sendo que o voluntário pode ter dor muscular ou dor no ombro após o teste. Assim, um examinador estará constantemente ao seu lado se eventualmente alguma ajuda for necessária durante execução dos testes. Você não será submetida a nenhum procedimento sem o seu conhecimento e consentimento, bem como receberá indenização diante de eventuais danos decorrentes da pesquisa conforme leis vigentes no país. 


\section{Liberdade de participação e sigilo de identidade}

A participação no estudo é totalmente voluntária, e você pode interrompê-la a qualquer momento sem nenhum prejuízo ao seu filho, e por obrigação, os pesquisadores responsáveis excluirão todos os dados. Todos os dados pessoais e informações obtidas neste estudo serão confidenciais, e nenhum nome será divulgado em momento algum. Entretanto, os dados obtidos poderão ser utilizados para fins didáticos e científicos, desde que seu anonimato seja resguardado.

Para qualquer dúvida durante todas as fases da pesquisa, favor contatar:

-Felipe de Souza Serenza.

Mestrando do Programa de Pós Graduação em Reabilitação e Desempenho Funcional da Faculdade de Medicina de Ribeirão Preto (FMRP/USP).

Fone: (16) 984835973 ou pelo e-mail: fsserenza@gmail.com

Para esclarecimentos éticos da pesquisa:

Comitê de Ética em Pesquisa do Comitê de Ética da EEFERP/USP: (16) 3315-0494, cep90@usp.br

$\mathrm{Eu}$,

$\mathrm{RG}$ data de nascimento na cidade residente estado

telefone (_ concordo em participar da pesquisa em que os responsáveis me explicaram todos os riscos envolvidos, o objetivo da pesquisa, se prontificaram a responder todas as minhas dúvidas sobre os procedimentos, além de entregar uma via deste Termo de Consentimento Livre e Esclarecido.

Ribeirão Preto, de de 